\title{
Fueling export production: nutrient return pathways from the deep ocean and their dependence on the Meridional Overturning Circulation
}

\author{
J. B. Palter ${ }^{1}$, J. L. Sarmiento ${ }^{1}$, A. Gnanadesikan ${ }^{2}$, J. Simeon ${ }^{3}$, and R. D. Slater ${ }^{1}$ \\ ${ }^{1}$ Atmospheric and Oceanic Sciences Program, Princeton University, Princeton, New Jersey, USA \\ ${ }^{2}$ Geophysical Fluid Dynamics Laboratory, Princeton, New Jersey, USA \\ ${ }^{3}$ Laboratoire des Sciences du Climat et de l'Environnement, CEN Saclay, 91191 Gif-sur-Yvette, France
}

Received: 9 May 2010 - Published in Biogeosciences Discuss.: 1 June 2010

Revised: 30 September 2010 - Accepted: 8 October 2010 - Published: 10 November 2010

\begin{abstract}
In the Southern Ocean, mixing and upwelling in the presence of heat and freshwater surface fluxes transform subpycnocline water to lighter densities as part of the upward branch of the Meridional Overturning Circulation (MOC). One hypothesized impact of this transformation is the restoration of nutrients to the global pycnocline, without which biological productivity at low latitudes would be significantly reduced. Here we use a novel set of modeling experiments to explore the causes and consequences of the Southern Ocean nutrient return pathway. Specifically, we quantify the contribution to global productivity of nutrients that rise from the ocean interior in the Southern Ocean, the northern high latitudes, and by mixing across the low latitude pycnocline. In addition, we evaluate how the strength of the Southern Ocean winds and the parameterizations of subgridscale processes change the dominant nutrient return pathways in the ocean. Our results suggest that nutrients upwelled from the deep ocean in the Antarctic Circumpolar Current and subducted in Subantartic Mode Water support between 33 and $75 \%$ of global export production between $30^{\circ} \mathrm{S}$ and $30^{\circ} \mathrm{N}$. The high end of this range results from an ocean model in which the MOC is driven primarily by windinduced Southern Ocean upwelling, a configuration favored due to its fidelity to tracer data, while the low end results from an MOC driven by high diapycnal diffusivity in the pycnocline. In all models, nutrients exported in the SAMW layer are utilized and converted rapidly (in less than 40 years)
\end{abstract}

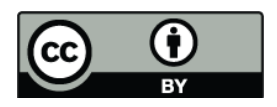

Correspondence to: J. B. Palter (jpalter@princeton.edu) to remineralized nutrients, explaining previous modeling results that showed little influence of the drawdown of SAMW surface nutrients on atmospheric carbon concentrations.

\section{Introduction}

Primary productivity in the ocean's sunlit surface incorporates dissolved nutrients into organic matter, a fraction of which sinks to the ocean interior. Once in the ocean's dark interior, the organic matter is respired back to dissolved inorganic carbon and nutrients, thereby creating the pervasive vertical nutrient and carbon gradients that characterize the global ocean. In and above the pycnocline (nominally above the $1026.8 \mathrm{~kg} \mathrm{~m}^{-3}$ potential density surface), the total inventory of phosphate, an essential nutrient for photosynthesis, is approximately $150 \mathrm{Tmol}$ (Conkright et al., 2001). Recent estimates of the sinking flux of organic phosphorus (Dunne et al., 2007), propagated to the depth of this density surface, are of order $3 \mathrm{Tmol} \mathrm{yr}^{-1}$. Thus, to prevent the upper ocean from becoming entirely depleted of phosphate, the nutrient must be returned to the upper ocean on time scales of approximately 50 years. We hypothesize that the upward branch of the Meridional Overturning Circulation (MOC), which converts dense deep waters to lighter pycnocline waters, plays a central role in maintaining the primary productivity of the upper ocean by returning exported nutrients to depths where they can again become accessible to the ocean's sunlit upper reaches. On long time scales, the MOC's upward branch balances the sinking of deep waters and is driven by a combination of vertical mixing across the low latitude pycnocline and

Published by Copernicus Publications on behalf of the European Geosciences Union. 
wind-driven upwelling and mixing in the Southern Ocean (Kuhlbrodt et al., 2007). However, the relative magnitude of the low latitude pathway versus the Southern Ocean pathway remains an open question, as does the implication for the cycling of nutrients. Here, we explore the MOC nutrient return pathways in a suite of ocean general circulation models with different physical parameterizations, seeking an understanding of the balance between the Southern Ocean nutrient pathway versus the low latitude pathway and the sensitivity of this balance to model physics.

A dominant role for the Southern Ocean in the MOC's upward branch has formerly been hypothesized based on tracer data (Toggweiler et al., 1991; Sarmiento et al., 2004, 2007) in the context of theoretical considerations of ocean overturning (Toggweiler and Samuels, 1995, 1998; Gnanadesikan, 1999). In terms of nutrient cycling, this hypothesis implies a loop in which the global loss of organic matter to depths beneath the pycnocline is largely balanced by the upwelling of remineralized nutrients in the Antarctic Circumpolar Current (ACC). These nutrients are then advected and mixed across the ACC into the Subantarctic Mode Water (SAMW), a water mass formed on the ACC's equatorward fringes that influences tracer properties throughout much of the global pycnocline (McCartney, 1982; Sarmiento et al., 2004; Hanawa and Talley, 2001). This conceptual model hinges on the upwelled nutrients being subducted with the SAMW at the time it forms, rather than being utilized and exported from it, as can be the case for other mode waters (Palter et al., 2005). Indeed, the SAMW is formed in a region with highly elevated surface nutrients (Fig. 1a), and it tends to retain its nutrients during formation and subduction. Evidence supporting the dominance of the Southern Ocean nutrient upwelling pathway has been obtained by model sensitivity studies, in which the strength of global primary production was critically reduced by completely stripping nutrients from the surface ocean in the SAMW formation region (Sarmiento et al., 2004; Marinov et al., 2006).

Additional support for the importance of a Southern Ocean upward MOC branch in influencing pycnocline nutrient concentrations comes from looking at quasi-conservative combinations of nutrient tracers. For example, in the Subantarctic Zone where SAMW is formed, phosphate $\left(\mathrm{PO}_{4}^{3-}\right)$ and nitrate $\left(\mathrm{NO}_{3}^{-}\right)$are abundant, while silicic acid $\left(\mathrm{Si}(\mathrm{OH})_{4}\right)$ is nearly depleted. Thus, a useful tracer of the SAMW is $\mathrm{Si}^{*}=\mathrm{Si}(\mathrm{OH})_{4}-\mathrm{NO}_{3}^{-}$(Sarmiento et al., 2004). The lowest $\mathrm{Si}^{*}$ concentrations in the global surface ocean are found in the SAMW formation region (Fig. 1b). Sarmiento et al. (2004) argue that because $\mathrm{Si}^{*}$ is approximately conserved in the ocean interior, the subsurface pool of negative $\mathrm{Si}^{*}$ indicates the spreading of SAMW via advective and diffusive transport processes throughout much of the South Pacific, Indian and low latitude Atlantic Oceans (Fig. 1c).
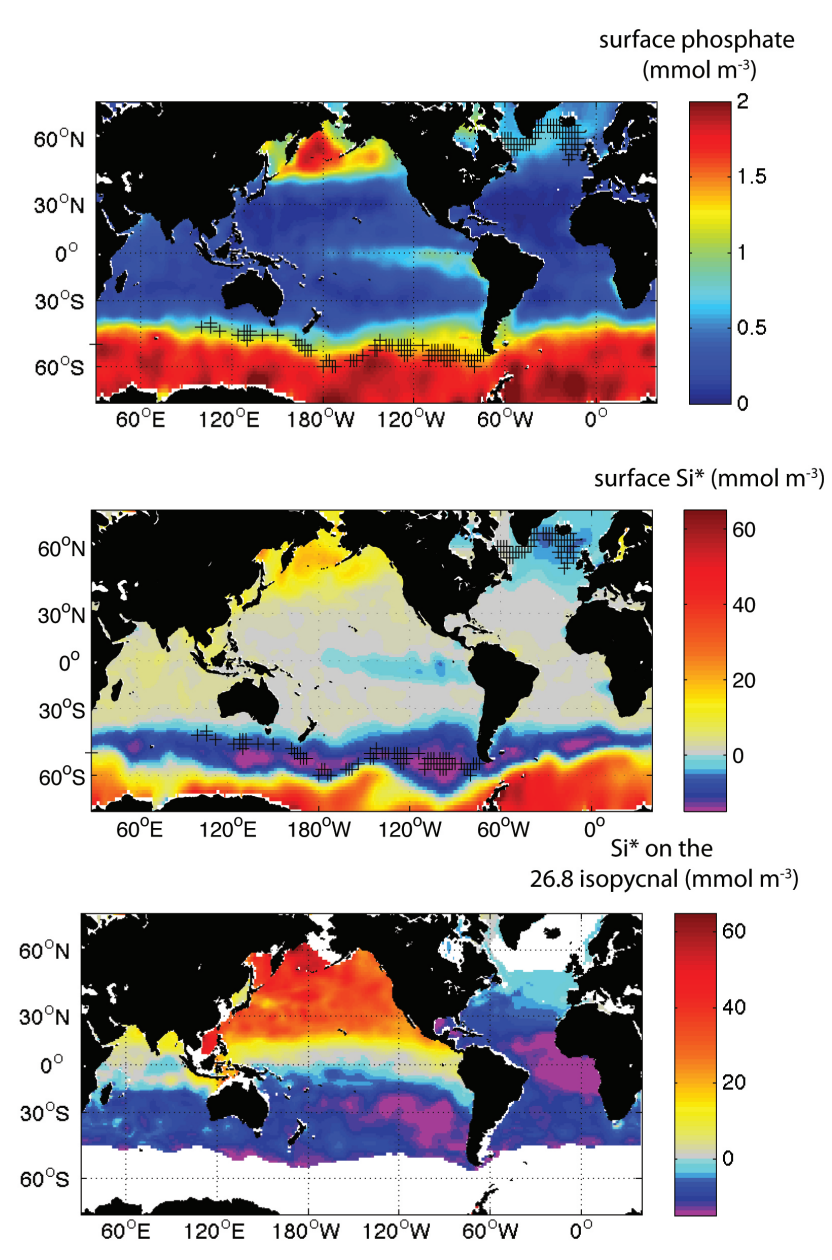

Fig. 1. Global nutrients at the ocean's surface and in the SAMW layer. (a) Surface phosphate from WOA01 (Conkright et al., 2001). (b) Surface Surface $\mathrm{Si}^{*}=\mathrm{Si}(\mathrm{OH})_{4}-\mathrm{NO}_{3}^{-}$from WOA01. (c) $\mathrm{Si}^{*}$ on the 26.8 isopycnal, at the center of the SAMW layer. In panels (a) and (b), black hatches indicate regions between $65^{\circ} \mathrm{S}$ and $65^{\circ} \mathrm{N}$ where annual maximum mixed layer depths exceed $400 \mathrm{~m}$, where mixed layer depths are taken from de Boyer Montégut et al. (2004). Panel (c) is recreated after Sarmiento et al. (2004). The white area represents the region where the annual mean surface density exceeds $1026.8 \mathrm{~kg} \mathrm{~m}^{-3}$

Despite the apparent convergence of evidence from models and the $\mathrm{Si}^{*}$ tracer towards a central role for a Southern Ocean nutrient return pathway from the deep ocean to the pycnocline, several important questions still require evaluation and quantification. What is the fraction of low latitude productivity sustained by the Southern Ocean nutrient return pathway and which water masses are involved? In which regions are the SAMW nutrients most important, and what are the pathways by which the SAMW arrives at these downstream locales? Here we examine these questions using a suite of ocean general circulation models (OGCMs). A second class of questions concerns the sensitivity of the predominant nutrient return pathway to the 
models' parameterizations of subgridscale processes and the prescribed atmospheric forcing that drives the ocean circulation, particularly the Southern Ocean winds. The fraction of deep upwelling that occurs in the Southern Ocean is sensitive to the strength of the winds, as well as the turbulent mixing and transport due to mesoscale eddies, which are parameterized in the coarse GCMs typically used to simulate climate and biogeochemistry. The sensitivity of the modeled MOC to winds and subgridscale processes has been demonstrated in more than one idealized analytical model (Gnanadesikan, 1999; Samelson, 2004, 2009), and tested in a suite of GCMs (Gnanadesikan et al., 2007). Here we quantify the sensitivity of the magnitude and distribution of nutrient supply to wind forcing and the parameterizations of subgridscale processes.

We also consider the implication of these results for nonsteady behavior by investigating the lateral and temporal scales over which the preformed nutrients subducted in the SAMW layer persist in the ocean interior before fueling downstream primary productivity. Preformed nutrients are those inorganic nutrients that enter the ocean interior without having fueled primary productivity while in the mixed layer. Therefore, preformed nutrients are a signature of inefficiency in the biological pump. A more efficient biological pump utilizes a greater portion of surface nutrients, converts them to organic material and increases the remineralized nutrient and carbon concentration deeper in the water column. Higher remineralized nutrient concentrations signify greater ocean carbon storage and lower atmospheric carbon dioxide, while a higher preformed nutrient inventory signals a smaller ocean carbon reservoir (Archer et al., 2000; Ito and Follows, 2005; Gnanadesikan and Marinov, 2008; Marinov et al., 2008a, b). Much of the SAMW nutrients enter the ocean in their preformed state, but when they fuel productivity downstream of their formation region, these inorganic nutrients are incorporated to organic matter and eventually converted to their remineralized state. Any increase in the subduction of the SAMW preformed nutrient pool would diminish the deep ocean carbon reservoir until these preformed nutrients are converted to their remineralized form. Evaluation of this potential for change in the ocean preformed nutrient reservoir is especially timely given recent observations showing the intensification of Southern Hemisphere westerly wind strength (Thompson and Solomon, 2002) with implications for the stability of the ocean carbon sink (Le Quéré et al., 2007). Such an intensification is expected to increase the cross-ACC Ekman transport of preformed nutrients, the preformed nutrient load of the SAMW, and the local inefficiency of the biological pump due to the subducted preformed nutrients in the mode and intermediate waters. Our model experiments shed light on the time scale that this perturbation might be expected to persist.

\section{The theory, the models, and the experimental design}

\subsection{The theory}

A simple conceptual model of the MOC consists of four branches: (1) deep water formation regions in the North Atlantic where surface waters become denser and sink; (2) flow away from these regions at depth; (3) upwelling and mixing that transports the dense waters from the ocean interior to the surface ocean; and (4) near-surface currents that close the circulation. Where and by what forcing mechanism the deep water returns to the surface (branch 3 ) is a central question in physical oceanography (for an extensive review see Kuhlbrodt et al., 2007), and, increasingly, motivates ocean biogeochemical and climate studies (Gnanadesikan et al., 2002; Sarmiento et al., 2007; Anderson et al., 2009). The two forcing mechanisms that have received the most attention are the downward mixing of heat and associated upwelling across the pycnocline (see Munk and Wunsch, 1998 for a detailed discussion) and the wind-driven upwelling of deep waters in the Southern Ocean and their subsequent buoyancy gain at the surface of the ocean (Toggweiler and Samuels, 1993, 1995). Gnanadesikan (1999) proposed a simple model that nicely synthesizes these two mechanisms into a single framework by relating the large-scale MOC to winds, eddies, and diapycnal mixing, as schematized in Fig. 2. The underpinning of the theory is that along-isopycnal eddy transport, diapycnal mixing, and wind forcing all determine where dense water returns to the ocean's surface, while the interplay of all three factors determines the depth and thickness of the pycnocline and the strength of the overturning cell.

For the modern ocean, the Gnanadesikan (1999) theory can be summarized as follows. Dense water forms and sinks in the high latitude North Atlantic and is exported southward in the deep limb of the MOC, a flux represented in the schematic as $M_{\mathrm{n}}$. All along its export pathways, the downward mixing of heat transforms the dense water to lighter densities and forces an upward volume flux represented as $M_{\mathrm{u}}$ that reduces the deep southward flow as it approaches the Southern Ocean. This upward flux scales as:

$M_{\mathrm{u}}=\frac{K_{\mathrm{v}} A}{D}$,

where $K_{\mathrm{V}}$ is the coefficient of diapycnal diffusion, $D$ is the pycnocline depth that separates dense water from light, and $A$ is the area of the low latitude pycnocline.

In the Southern Ocean, laterally divergent Ekman transport forces the upwelling of abyssal waters, a flux represented as $M_{\mathrm{s}}$. The upwelled waters that cross the ACC into the SAMW formation region gain buoyancy along their journey, thus completing the dense-to-light transformation of the water masses formed in the North Atlantic. However, adding another layer of complexity, a volume transport due to mesoscale eddies is directed southward across the ACC, balancing some fraction of the northward Ekman transport. 

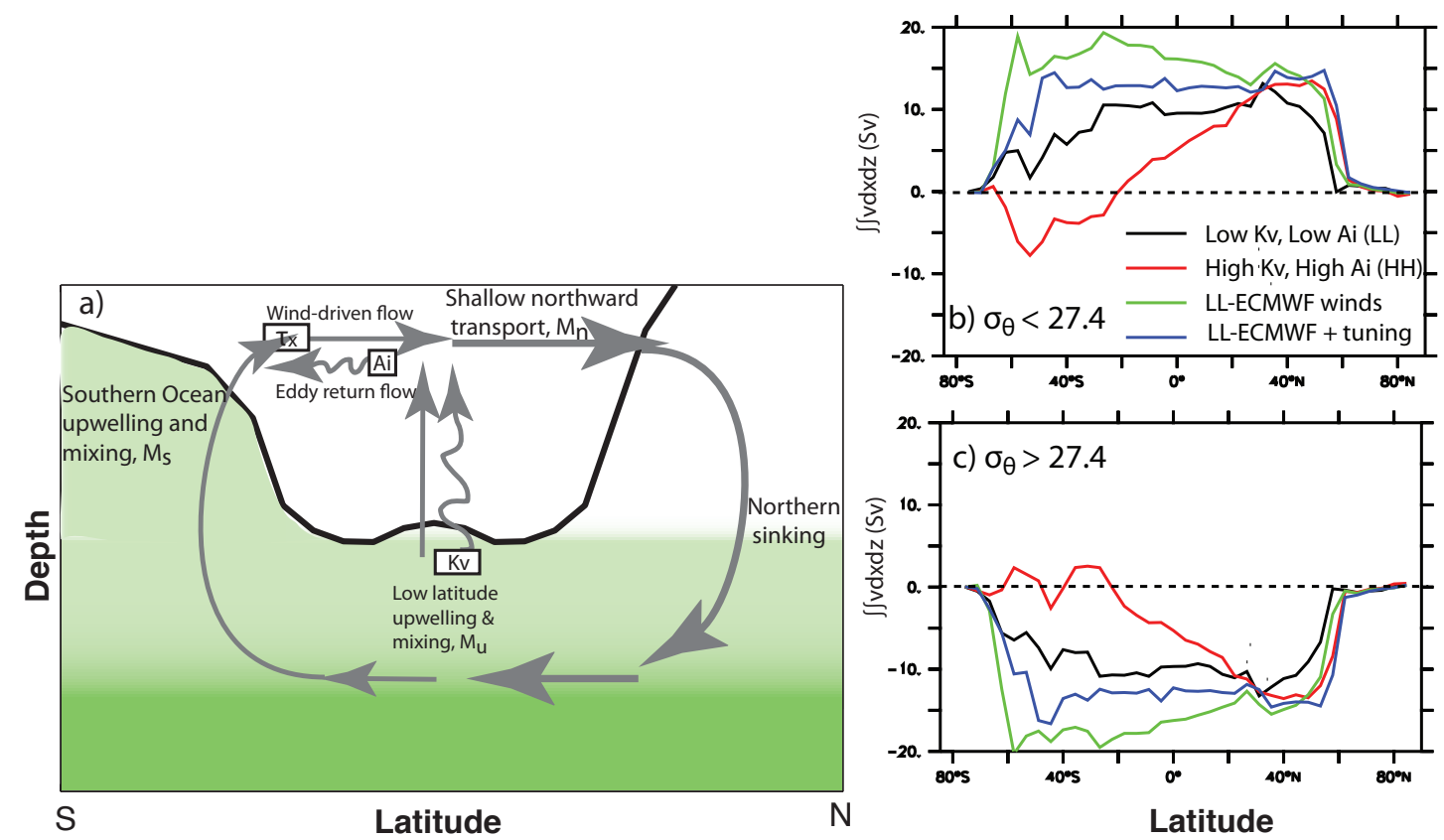

Fig. 2. Schematic of the simple analytical model of the Meridional Overturning Circulation (MOC) and the model results of the MOC. (a) Adapted from Gnanadesikan (1999), the schematic of the flows (gray arrows) which comprise the MOC and their driving mechanisms (boxed text). The black line schematizes the global pycnocline, below which nutrient-rich water is found, represented by green shading. The sinking of water masses in the Northern Hemisphere is balanced by the sum of the Southern Ocean upwelling ( $\left.M_{\mathrm{S}}\right)$ and low latitude upwelling $\left(M_{\mathrm{u}}\right)$. The rate of Southern Ocean upwelling is set by the wind stress over the Southern Ocean $\left(\tau_{x}\right)$ and the eddy return flow, which is determined largely by the GM coefficient $\left(A_{i}\right)$. The low latitude upwelling is driven by the downward mixing of heat, which is set by the vertical mixing coefficient $\left(\kappa_{\mathrm{V}}\right)$. (b) The zonally integrated meridional transport above the 27.4 isopycnal (northward is positive) for each of the four models described in Table 1. (c) The same as panel (b), but below the 27.4 isopycnal. By design, panels (b) and (c) are mirror images of one another because the total transport sums to zero for the volume-conserving ocean of the GCMs. A meridional increase in the meridional transport above (below) the 27.4 isopycnal signals the upwelling (downwelling) of water across the 27.4 isopycnal. The four models are described in Sect. 2.2 of the text and in Table 1.

The eddy transport is thought to be proportional to the local slope of isopycnals, which is the source of potential energy from which the eddies grow (Gent and McWilliams, 1990). Thus, the flux of abyssal water to the light water realm in the Southern Ocean, $M_{\mathrm{s}}$, is equal to the difference between the Ekman transport $M_{\mathrm{ek}}$ and the residual mass flux due to the eddies:

$M_{\mathrm{s}}=M_{\mathrm{ek}}-\frac{A_{i} D L_{x}}{L_{y}^{S}}$

where $A_{i}$ is a coefficient that determines the strength of the eddy mass transport, $L_{y}^{S}$ is the north-south scale over which the pycnocline shallows in the Southern Ocean, and $L_{x}$ is the Earth's circumference at the Drake Passage latitude (see also Karsten and Marshall, 2002).

For the limiting case in which the eddy transport across the ACC is as large as the Ekman transport, the net Southern Ocean deep water return pathway becomes negligible and the upward branch of the MOC must be accomplished exclusively through low latitude diapycnal mixing; this is the picture of the MOC hypothesized by Stommel and Arons (1961). For the alternate limiting case in which global diapycnal mixing is, on average, as small as the diapycnal mixing measured in the ocean away from topography (Gregg and Sanford, 1980; Ledwell et al., 1993, 1998), the Ekman upwelling of dense waters in the Southern Ocean and their buoyancy gain provide the primary driver of meridional overturning (Toggweiler and Samuels, 1998). We note that this conceptual model does not explicitly consider spatial variability in the strength of diapycnal mixing observed in the ocean (Heywood et al., 2002; Naveira Garabato et al., 2004), although the model framework outlined below allows for some exploration of this variability.

\subsection{The models}

The underlying architecture used to probe our questions is a suite of simulations using the Geophysical Fluid Dynamics Laboratory Modular Ocean Model version 3 (MOM3) (Pacanowski and Griffies, 1999). The MOM3 suite explores a range of mixing parameters and wind forcing, as described in several previous studies (Gnanadesikan, 1999; Gnanadesikan et al., 2004, 2007; Mignone et al., 2006), and summarized in Table 1. The models create variants of the MOC 
Table 1. Description of the four ocean GCMs. Model acronyms are described in the text. Differences from LL are highlighted in italic.

\begin{tabular}{|c|c|c|c|c|}
\hline Configuration: & $\begin{array}{l}\text { LL } \\
\text { (Low diapycnal } \\
\text { diffusivity; } \\
\text { Low GM coefficient) }\end{array}$ & $\begin{array}{l}\text { HH } \\
\text { (High diapycnal } \\
\text { diffusivity; } \\
\text { High GM coefficient) }\end{array}$ & $\begin{array}{l}\text { LL-ECMWF } \\
\text { (Low diapycnal } \\
\text { diffusivity; Low GM } \\
\text { coefficient; ECMWF } \\
\text { winds, stronger in } \\
\text { S. Ocean) }\end{array}$ & $\begin{array}{l}\text { P2A } \\
\text { (Low diapycnal diffusivity } \\
\text { outside the top } 50 \mathrm{~m} \text {; } \\
\text { Low GM coefficient; } \\
\text { ECMWF winds, stronger in } \\
\text { S. Ocean; several additional } \\
\text { modifications) }\end{array}$ \\
\hline $\begin{array}{l}\text { Diapycnal diffusivity } \\
\text { (tropics) }\left(\mathrm{m}^{2} \mathrm{~s}^{-1}\right)\end{array}$ & $1.5 \times 10^{-5}$ & $6 \times 10^{-5}$ & $1.5 \times 10^{-5}$ & $1.5 \times 10^{-5}$ \\
\hline $\begin{array}{l}\text { Diapycnal diffusivity } \\
\text { (Southern Ocean) } \\
\left(\mathrm{m}^{2} \mathrm{~s}^{-1}\right)\end{array}$ & $1.5 \times 10^{-5}$ & $6 \times 10^{-5}$ & $1.5 \times 10^{-5}$ & $13 \times 10^{-5}$ \\
\hline $\begin{array}{l}\text { Enhanced diffusivity } \\
\text { in top } 50 \mathrm{~m}\end{array}$ & No & No & No & Yes \\
\hline $\begin{array}{l}\text { Along isopycnal } \\
\text { diffusivity AND } \\
\text { coefficient for GM } \\
\text { thickness diffusion } \\
\left(\mathrm{m}^{2} \mathrm{~s}^{-1}\right)\end{array}$ & 1000 & 2000 & 1000 & 1000 \\
\hline $\begin{array}{l}\text { Applied surface } \\
\text { moisture fluxes }\end{array}$ & Da Silva et al. (1994) & Da Silva et al. (1994) & Da Silva et al. (1994) & $\begin{array}{l}\text { Da Silva et al. (1994) } \\
\text { plus correction globally }\end{array}$ \\
\hline $\begin{array}{l}\text { Temperature and } \\
\text { salinity toward which } \\
\text { restoring occurs }\end{array}$ & Levitus et al. (1994) & Levitus et al. (1994) & Levitus et al. (1994) & $\begin{array}{l}\text { Levitus et al. (1994) } \\
\text { plus correction factor } \\
\text { near Antarctica in winter }\end{array}$ \\
\hline Wind stress & Hellerman & Hellerman & $E C M W F$ & $E C M W F$ \\
\hline Topography & Wide Drake Passage & Wide Drake Passage & Wide Drake Passage & Narrow Drake Passage \\
\hline
\end{tabular}

strength and structure by changing: (a) the Southern Ocean Ekman transport, $M_{\mathrm{ek}}$, via the use of two different wind reanalysis products to force the model; (b) the counterbalancing eddy transport via the manipulation of $A_{i}$, the coefficient associated with the Gent and McWilliams (1990) (GM) parameterization of eddy transport; and (c) the diapycnal mixing across the low latitude pycnocline via variations in $K_{\mathrm{V}}$, the coefficient of diapycnal diffusion. Here we present the results from a subset of four models from a larger MOM3 suite explored in Gnanadesikan et al. (2007), chosen because they capture much of the inter-model differences of the full parameter range without being excessively cumbersome for comparison.

Two of the models are forced with wind stresses from Hellerman and Rosenstein (1983), which are approximately half as intense in the Southern Ocean as the European Centre for Medium-Range Weather Forecasts (ECMWF) climatological winds (Trenberth et al., 1989) used to force the other two models. Of these Hellerman and Rosenstein-forced models, one is run with a Low $K_{\mathrm{v}}$ and Low $A_{i}$, and is therefore referred to as LL; the other has a High $K_{\mathrm{v}}$ and High $A_{i}$, and is referred to as HH. LL-ECMWF is identical to the LL model in the ocean, but is forced with ECMWF winds. A special case we call $\mathrm{P} 2 \mathrm{~A}$ resembles the LL-ECMWF model but has been modified in several ways intended to increase the realism of the simulation: the Drake Passage was narrowed from three grid points $(1165 \mathrm{~km})$ to two $(777 \mathrm{~km})$ to be closer to the real Drake Passage, which is $800 \mathrm{~km}$ wide; strong vertical mixing $\left(5 \times 10^{-3} \mathrm{~m}^{2} \mathrm{~s}^{-1}\right)$ is imposed on the uppermost two grid cells $(50 \mathrm{~m})$ as a very crude approximation to what actually occurs in an oceanic mixed layer; and surface salinity is strongly restored to subsurface observations in four key locations at the onset of Austral winter in Southern Ocean deep water formation regions to simulate brine rejection during sea-ice formation. Without this salinity adjustment, restoring the model to observations suppresses Antarctic Bottom Water (AABW) formation, as the observations do not capture the outcropping of such waters. Finally, in P2A the coefficient of diapycnal mixing is increased in the Southern Ocean, first motivated by observations of intense ACC internal wave activity (Polzin, 1999) and later validated by observations of rapid diapycnal 
tracer spreading in the region (Naveira Garabato et al., 2004). Clearly the MOC strength and upward branch is controlled by the interplay of these parameter choices (Fig. 2b-c), with the MOC in the $\mathrm{HH}$ model confined entirely to the region north of $20^{\circ} \mathrm{N}$, while the LL-ECMWF overturning is actually intensified in the Southern Hemisphere. We will explore the MOC differences among the models at greater length in Sect. 3 .

A model of the biological cycling of phosphorus and carbon is coupled to the physical model, as specified by the Ocean Carbon Model Intercomparison Project-2 (OCMIP2) protocol (Najjar et al., 2007). In this protocol, phosphorus is the only simulated nutrient and is conserved globally in all experiments. The phosphorus source/sink terms are governed by an extremely simple set of equations meant to represent the incorporation of phosphate into organic matter by photosynthesis in the euphotic zone and the sinking of this organic matter and its remineralization back to phosphate throughout the water column (Fig. 3). The simulated phosphorus appears in 2 pools: dissolved organic phosphorus (DOP) and phosphate $\left(\mathrm{PO}_{4}^{3-}\right)$. These pools are transported as passive tracers by the physical model. At depths shallower than $75 \mathrm{~m}$, the model $\mathrm{PO}_{4}^{3-}$ in excess of a seasonal $\mathrm{PO}_{4}^{3-}$ climatology (Louanchi and Najjar, 2000) fuels primary production, represented by restoring the surface model $\mathrm{PO}_{4}^{3-}$ to climatological values over a time scale of $\tau=30$ days. The resulting production has two fates: two thirds becomes a source term for DOP and one third fuels a parameterized sinking flux of organic phosphorus that is shunted to $75 \mathrm{~m}$. Below $75 \mathrm{~m}$, the sinking flux decays as a function of depth and its vertical divergence is a source term of $\mathrm{PO}_{4}^{3-}$. DOP is remineralized to $\mathrm{PO}_{4}^{3-}$ everywhere in the model, at a rate of $\kappa=0.5$ year $^{-1}$.

\subsection{The experimental design}

To investigate the role of the upward branch of the MOC in the supply of nutrients to the low latitude pycnocline and ultimately the euphotic zone, we created two sets of tags that are schematized in Fig. 4. The first is a simple set of dye tracers. In each tagging region (represented in black in the schematics), the dye value is set to one; in each destruction region (white in the schematics), the dye value is set to zero; in the rest of the domain (gray in the schematics), the dye tags are treated as conserved, passive tracers. The dyes are named according to their source locations and are fully described in Fig. 4 and its caption. The physical model is spun up to a steady circulation before the dyes are released. All presented results are averages between year 190 and 200 after the release of the tags, except for LL-ECMWF, which are for years 390-400. The longer integration time for LL-ECMWF was chosen only because the appropriate terms were not archived until the later time period. At year 190, the drift in average low latitude dye concentrations is less than $0.1 \%$ year $^{-1}$, very

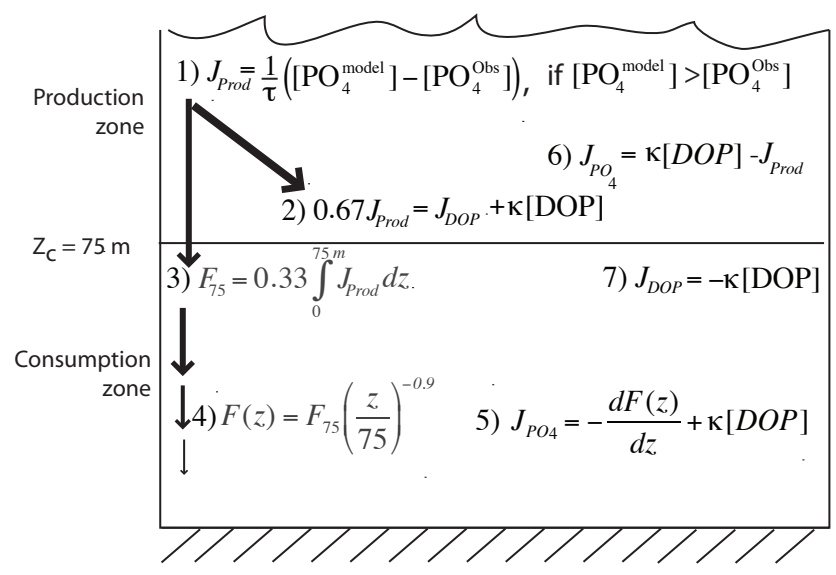

Fig. 3. A schematic showing the governing equations of the OCMIP-2 biological model. Terms that begin with the letter $J$ are source/sink terms (black text), while terms that begin with the letter $F$ are flux terms (grey text). At depths shallower than $75 \mathrm{~m}$, model $\mathrm{PO}_{4}^{3-}\left(\mathrm{PO}_{4}^{\text {model }}\right)$ in excess of a seasonal climatology $\left(\mathrm{PO}_{4}^{\mathrm{Obs}}\right)$ (Louanchi and Najjar, 2000) fuels new production ( $\left.J_{\text {Prod }}\right)$, thus restoring the surface model to climatological values over a time scale of $\tau=30$ days (Eq. 1). The resulting productivity has two fates: two thirds becomes a source term for DOP ( $J_{\mathrm{DOP}}$, Eq. 2$)$, and one third fuels a parameterized sinking flux of organic phosphorus, that is shunted to $75 \mathrm{~m}\left(F_{75}\right.$, Eq. 3). Below $75 \mathrm{~m}$, the sinking flux decays as a function of depth (Eq. 4). The vertical divergence of this sinking flux is a source term of $\mathrm{PO}_{4}^{3-}$ (Eq. 5). DOP is remineralized to $\mathrm{PO}_{4}^{3-}$ everywhere in the model, at a rate of $\kappa=0.5$ year- 1 (Eqs. 5 and 6). This DOP to $\mathrm{PO}_{4}^{3-}$ decay is a sink term for DOP $(-\kappa[\mathrm{DOP}]$, Eqs. 2 and 7$)$.

close to equilibrium, and almost all regions are fully tagged. After 200 years, only the water masses of the Bay of Bengal are not fully tagged (thus, the global sum of all tags can be slightly less than $100 \%$ ).

Outside the tagging and destruction regions (i.e. in and above the low latitude pycnocline), the dye tracers directly measure the fractions of water that derive from each tagging region. The abyssal ocean is tagged only in low latitudes and only at potential densities greater than $27.4 \mathrm{~kg} \mathrm{~m}^{-3}$, which is beneath the main thermocline in all models. The Northern Hemisphere High latitudes are tagged everywhere north of $40^{\circ} \mathrm{N}$, and further designated as stemming from the North Atlantic and North Pacific basins. In the Southern Ocean, the tags are divided into density classes in order to approximate the contribution of SAMW and AAIW to the low latitude pycnocline. By design, the southernmost tag is trapped in the Southern Ocean, and is used primarily to ensure that all water masses are tagged and a water mass budget can be balanced.

In the Southern Ocean, AAIW is most commonly identified as a salinity minimum along the 27.3 isopycnal. Because the SAMW is formed in large part by convective processes, it can be identified as a pycnostad, or region of low vertical density stratification. A comparison of our simulations 

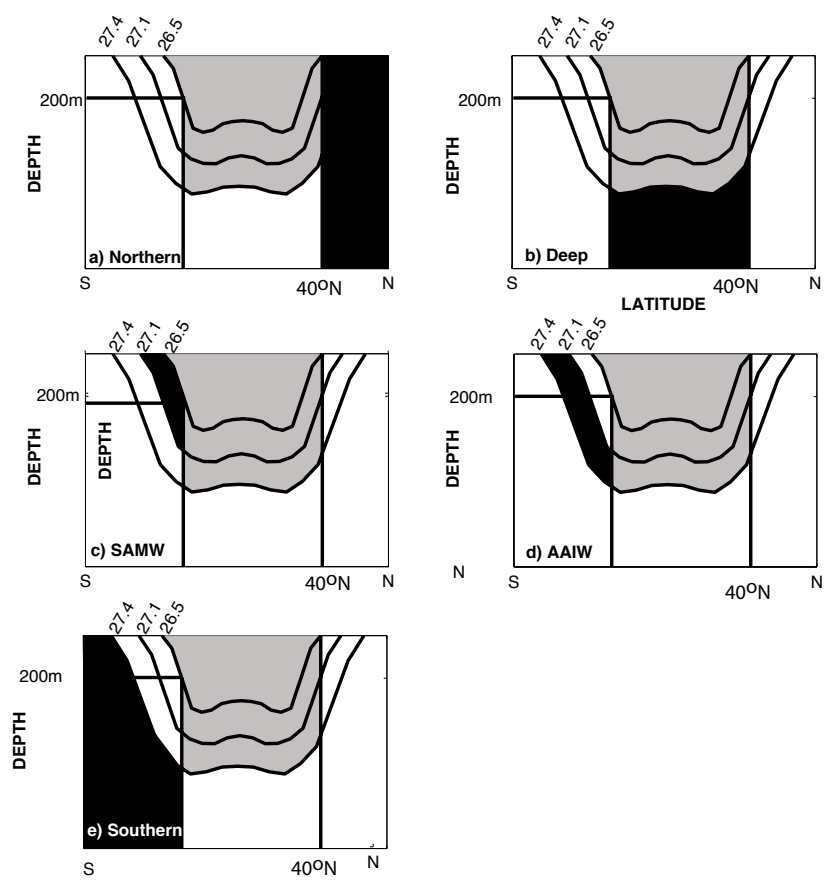

Fig. 4. A schematic of the experimental design used to examine the nutrient return pathways to the low latitude surface ocean. Each panel represents the deployment of a regional tag in zonal crosssection. The curvy lines represent selected isopycnals, as labeled at the top of each panel. In the black area, the dye tag, phosphate, and DOP are tagged according to the following conventions: (a) The Northern tag (which was further subdivided into North Atlantic and North Pacific) set on all water north of $40^{\circ}$ N. (b) The Deep Low latitude tag, set for all water with potential densities greater than 27.4 between $40^{\circ} \mathrm{N}$ and a southern boundary defined by the latitude where the 26.5 isopycnal intersects $200 \mathrm{~m}$. (c) The SAMW tag, set between that same boundary and the 27.1 isopycnal. (d) AAIW tag, set between the 27.1 and 27.4 isopycnals southward of the same boundary. (e) Southern tag for all water denser than AAIW and southward of the boundary. In the white areas, the tag is destroyed and set to its new region. In the gray areas, all tags behave according to their conservation equation.

with a well-studied salinity and density section along $100^{\circ} \mathrm{E}$ (Sloyan and Kamenkovich, 2007) (Fig. 5), reveals that the models do a good job simulating the salinity and stratification minima that characterize the AAIW and SAMW, respectively. The model density structure in the Southern Ocean resembles the observations, giving confidence that our Southern Ocean water mass definitions are appropriate to address the question at hand. It is also reassuring that the SAMW dye tracer on the 26.8 isopycnal shows a similar spatial distribution to the $\mathrm{Si}^{*}$ tracer from data (compare Fig. 6 with Fig. 1c). An exception to this similarity is in the degree of AtlanticPacific asymmetry. The $\mathrm{Si}^{*}$ tracer transitions to positive values at the equator in the Pacific, possibly a consequence of mixing processes in the Sea of Okhotsk that are not resolved by the models (Talley, 1991; Sarmiento et al., 2004). We note that the SAMW dye penetrates into the Northern Hemisphere in all of the models, regardless of whether there is net destruction or creation of light waters in the Southern Ocean. The differences among the models are largely seen in Indian Ocean, the equatorial Atlantic, and the western tropical Pacific where the HH model has 20-40\% less SAMW than the others (Fig. 6).

The second set of tags is designed to trace nutrients from the same source regions as the dyes. In each source region, all model $\mathrm{PO}_{4}^{3-}$ and DOP are tagged, or named according to their region, such that the total pools of $\mathrm{PO}_{4}^{3-}$ and DOP everywhere in the model domain are the sum of the regionallytagged pools. As an illustrative example, $\mathrm{PO}_{4}^{3-}$ and DOP are endowed with a SAMW tag between the 26.5 and 27.1 isopycnals in the Southern Hemisphere, southward of where the 26.5 isopycnal intersects $200 \mathrm{~m}$ (as for the SAMW dye tracer, shown in Fig. 4c).

As the SAMW-tagged DOP (hereafter SAMW DOP) is transported in the flow field from its tagging region, it is respired to a separate pool of remineralized SAMW phosphate. The same is true for the SAMW phosphate that fuels primary production downstream of its tagging domain: the remineralization of the resultant DOP and sinking flux provides a source of remineralized SAMW phosphate. Thus, although the phosphorus maintains its regional identity until it enters a destruction region, it is marked as either coming directly from the tagging region, which we will refer to as unmodified, or being created by remineralization away from the tagging region, which we refer to as remineralized. Unmodified nutrients in our experiments resemble preformed nutrients when they are tagged in the surface mixed layer and can shed light on the pathways and persistence of preformed nutrients in the ocean interior. Yet, we avoid the use of the word preformed to describe them, because the tags are not exclusively introduced in the mixed layer, and therefore our unmodified phosphate can differ from a traditional definition of preformed nutrients. This distinction becomes particularly apparent in our discussion of the unmodified deep low latitude phosphate, which is tagged only in the interior ocean, and therefore bears no resemblance to the traditional definition of preformed nutrients. Throughout this work, references to tagged nutrients and their unmodified and remineralized components will appear in italics for clarity.

In order to estimate the productivity sustained by the remineralized tagged nutrients, Eqs. (2) and (6) from Fig. 3 are differenced to above $75 \mathrm{~m}$ to arrive at the expression:

$J_{\mathrm{PROD}}^{\mathrm{tag}}=\frac{J_{\mathrm{DOP}}^{\mathrm{tag}}+J_{\mathrm{PO}_{4}}^{\mathrm{tag}}}{-0.33}$

This expression can be used to calculate the primary production fueled by each remineralized phosphate tag, $J_{\mathrm{PROD}}^{\mathrm{tag}}$. This result is divided by the total $J_{\mathrm{PROD}}$, which is archived by the model. According to this expression, a sink of $\mathrm{PO}_{4}^{3-}$ (i.e. negative $J_{\mathrm{PO}_{4}}$ ) is due to primary production, while a source 
a) Observations

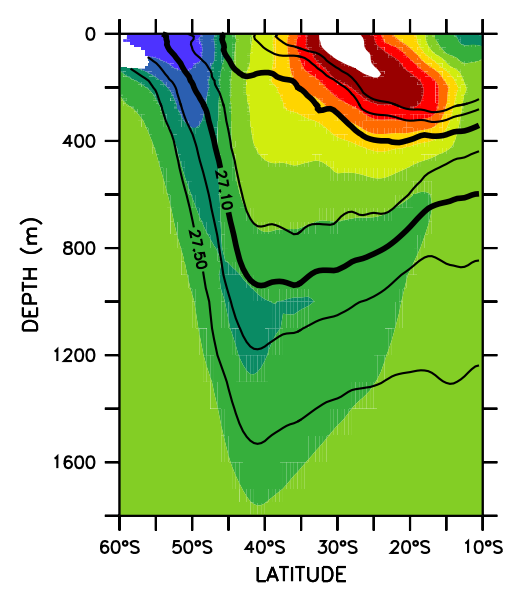

d) LL-ECMWF

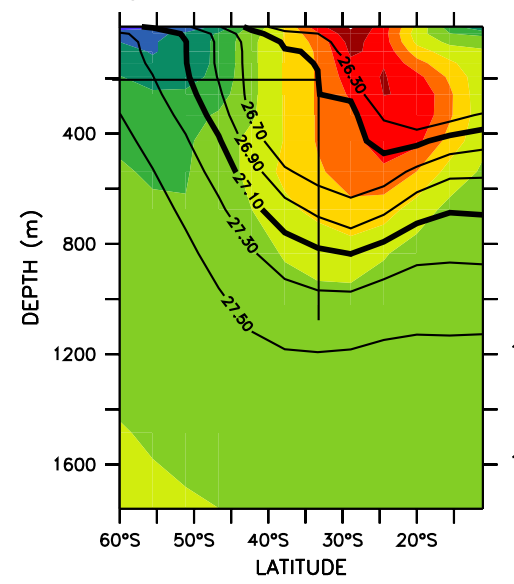

b) LL

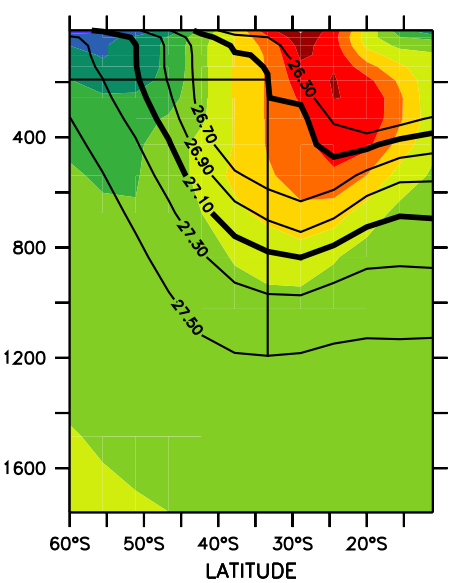

e) $\mathrm{P} 2 \mathrm{~A}$

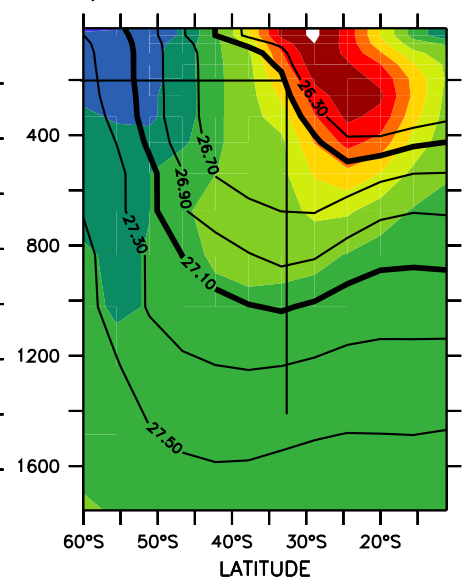

c) $\mathrm{HH}$

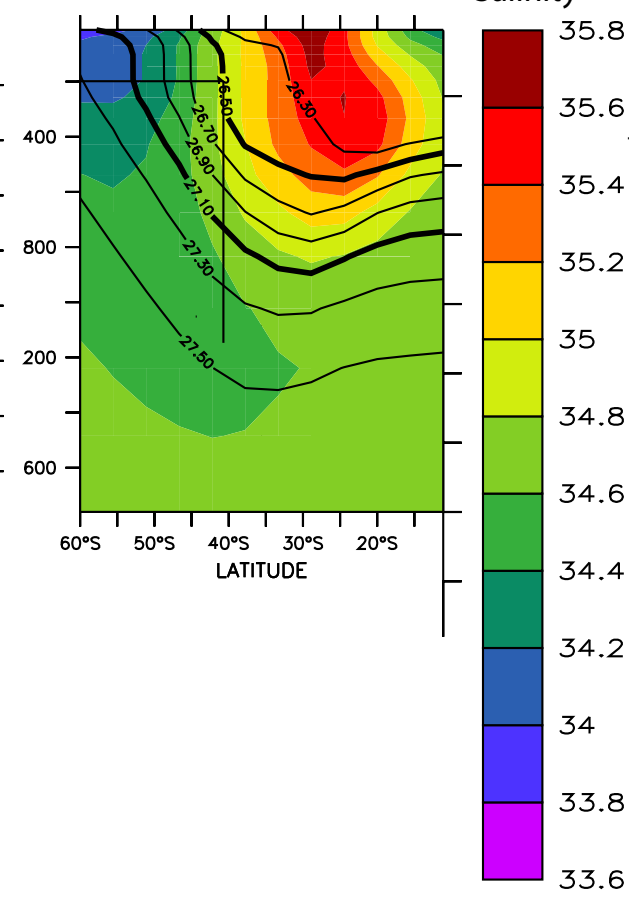

Fig. 5. Salinity (colors) and density (contours) along $100^{\circ} \mathrm{E}$ in (a) observations and (b-e) the 4 models, as labeled above each panel. The SAMW layer is visible as a pycnostad between the 26.5 and 27.1 isopycnals just north of the ACC, and the AAIW is characterized by a salinity minimum on the dense side of the SAMW. Observations taken from the CARS2006 database (Ridgway et al., 2002). Vertical lines show the time-mean boundary used to separate the SAMW tag region from the low-latitudes in the models.

of $\mathrm{PO}_{4}^{3-}$ (due to the remineralization of DOP to $\mathrm{PO}_{4}^{3-}$ ) is associated with negative production. Thus, the total $J_{\mathrm{PROD}}^{\mathrm{tag}}$ can be negative if the tagged DOP is remineralized to $\mathrm{PO}_{4}^{3-}$ at a greater rate than the tagged remineralized $\mathrm{PO}_{4}^{3-}$ fuels productivity.

\section{Results and discussion}

\subsection{Model circulation}

The simulated MOC in the different models behaves as predicted by the simple analytical model presented in Sect. 2.1. In all models, the interplay of the chosen parameter values creates a pycnocline with a realistic depth and density and an MOC at $48^{\circ} \mathrm{N}$ similar to the 16-19 Sv inferred from observations (Table 2) (Lumpkin and Speer, 2007; Talley, 2008; Forget, 2010). However, the upward branch of the MOC occurs at notably different locations among the models (Table 2). The LL model with its weak Southern Ocean winds and low mixing creates an MOC of $13.6 \mathrm{~Sv}$, with more than half of the upward branch supplied in the Southern Ocean; the $\mathrm{HH}$ model creates $17.9 \mathrm{~Sv}$ of overturning, but its upward branch is realized entirely at low latitudes; and the P2A and LL-ECMWF models also yield over $18 \mathrm{~Sv}$ of overturning, but with upward branches primarily in the Southern Ocean. Some observationally-driven inverse models (Lumpkin and Speer, 2007) and, more recently, the results from the dataassimilating forward model used in Estimating the Circulation and Climate of the Ocean (ECCO) (Wunsch and Heimbach, 2007; Forget, 2010) have suggested that the upward branch of the MOC is accomplished primarily in the Southern Ocean (Table 2). Yet, another observationally-driven estimate suggests a more important role for low latitude upwelling and implies values of low latitude diapycnal mixing 
a) Low-Low
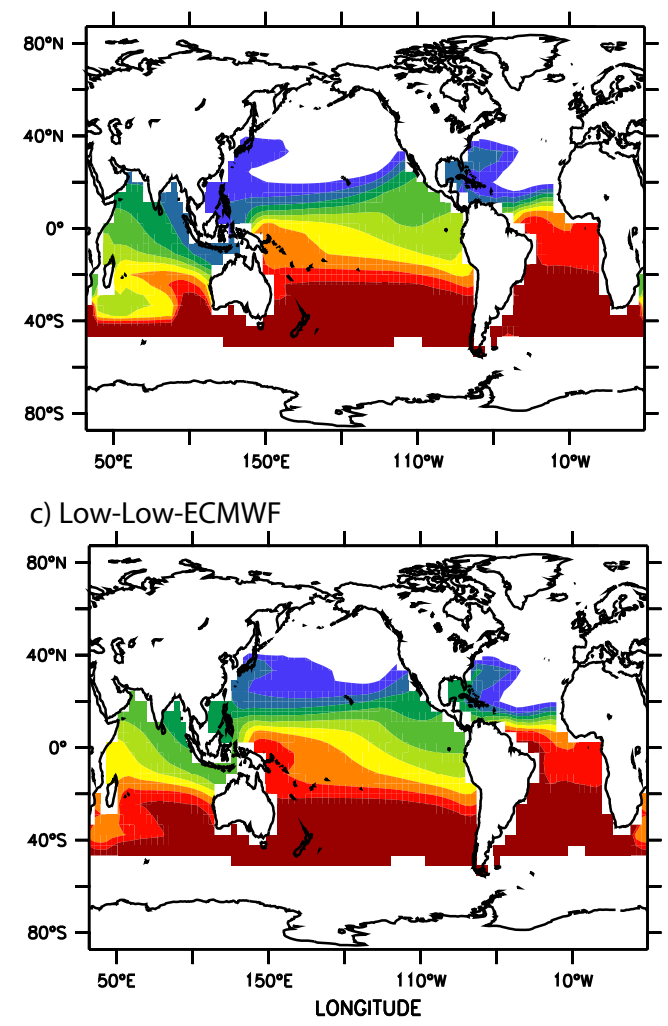

b) High-High

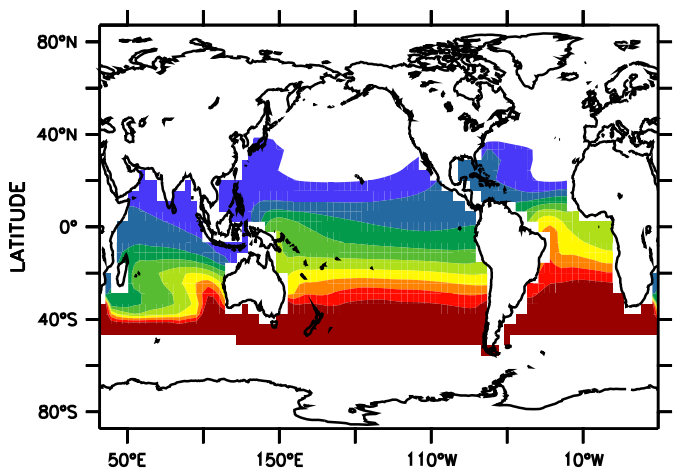

d) $P 2 A$

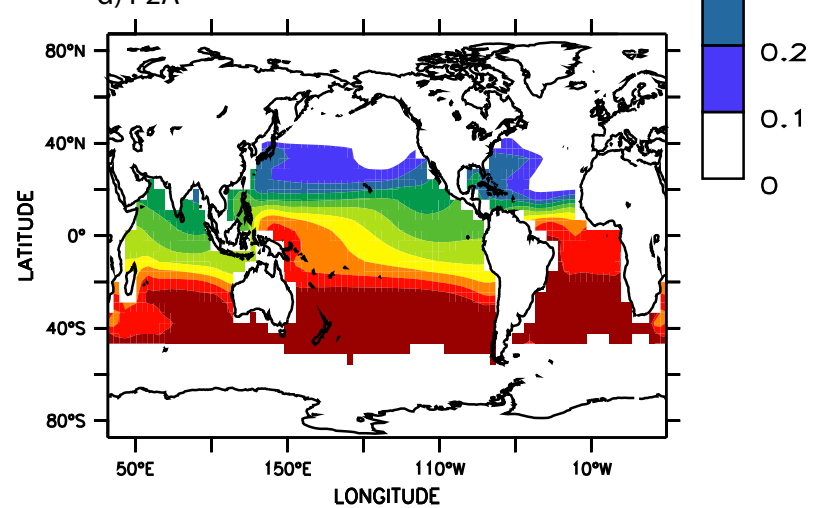

SAMW dye

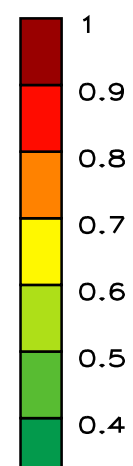

0.3

0.2

0.1

Fig. 6. SAMW dye fraction on the 26.8 isopycnal for the 4 models described in Table 1 and labeled at the top of each panel.

as high as in our HH model (Talley, 2008). Thus, the relative importance of these two possible upwelling branches lacks a definitive solution at present, providing a motivation for including in our analysis models that cover the range of possibilities. Furthermore, the modeled MOC has a direct influence on the large-range of air-sea $\mathrm{CO}_{2}$ fluxes estimated from coupled models (Cao et al., 2009).

Radiocarbon, a useful tracer of ocean circulation, offers evidence consistent with the upwelling of deep waters in the Southern Ocean. We briefly compare the radiocarbon results from our four models with observations to offer a context with which to judge the various circulations. Radiocarbon enters the ocean only at the air-sea interface and then decays in the ocean interior with a half-life of 5730 years. Thus, the most-recently ventilated ocean waters are most enriched in radiocarbon, and the oldest waters most depleted. The $\mathrm{HH}$ model strongly mixes waters depleted in radiocarbon from the dense ocean interior to the surface in subtropical latitudes, causing a depleted radiocarbon bias in the near-surface layers (Fig. 7, red line). This bias is reversed in the Southern Ocean, where the HH model overestimates the radiocarbon in the surface due an excessive supply of low latitude, high radiocarbon surface waters. Not surprisingly, the LL model, which is also forced with sluggish Southern Hemisphere westerly winds but has weaker diapycnal diffusivity and GM coefficients, has precisely the opposite bias: an underventilated deep ocean with a low radiocarbon bias, and corresponding radiocarbon trapping in the upper ocean. The P2A model with weak vertical mixing at low latitudes and high Southern Ocean winds and mixing is the most successful at accurately simulating the observed radiocarbon concentrations in the surface and deep ocean (Fig. 7, blue line). The P2A model is also the only one with an ACC transport at Drake Passage (126 Sv) in the range of observational estimates of $135 \pm 14 \mathrm{~Sv}$ (Cunningham et al., 2003); the other three models have a Drake Passage transport of approximately $80 \mathrm{~Sv}$. More extensive model-data comparison with the MOM3 suite can be found in a number of previous papers (Gnanadesikan et al., 2002, 2004; Matsumoto et al., 2004); all suggest a critical role for upwelling and/or mixing in the Southern Ocean in driving the MOC.

\subsection{Spreading of dye and nutrient tags}

Despite the differences among models, the SAMW comprises a sizeable fraction (45-68\%) of the low latitude waters above the 26.8 isopycnal in all models (Table 3 ). As predicted in the analytical framework, the HH model has the smallest SAMW fraction, as water from depths beneath the pycnocline (with the Deep Low latitude tag) upwells directly 
Table 2. Comparison of the pycnocline and MOC characteristics of the four models from the MOM3 suite and with estimates from observations.

\begin{tabular}{|c|c|c|c|c|c|}
\hline Metric: & LL & $\mathrm{HH}$ & LL-ECMWF & $\mathrm{P} 2 \mathrm{~A}$ & $\begin{array}{l}\text { Estimates from observations (including inverse } \\
\text { models and a data-assimilating forward model) }\end{array}$ \\
\hline $\begin{array}{l}\text { Pycnocline depth (m) })^{1} \\
D=\frac{2 \int_{0}^{2.5 \mathrm{~km}}\left(\sigma_{1 \mathrm{max}}-\sigma_{1}\right) z d z}{\int_{0}^{2.5 \mathrm{~km}}\left(\sigma_{1 \max }-\sigma_{1}\right) d z}\end{array}$ & 862 & 881 & 980 & 915 & $\begin{array}{l}834 \\
\text { estimated from Conkright et al. (2001) }\end{array}$ \\
\hline$\sigma_{\theta}$ at pycnocline depth ${ }^{1}$ & 27.31 & 27.25 & 27.32 & 27.28 & $\begin{array}{l}27.24 \\
\text { (Conkright et al., 2001) }\end{array}$ \\
\hline $\begin{array}{l}M_{\mathrm{n}}(\mathrm{Sv}): \text { max northward } \\
\text { transport summed vertically } \\
\text { from the surface at } 48^{\circ} \mathrm{N}\end{array}$ & 13.6 & 17.9 & 18.4 & 18.8 & $\begin{array}{l}19 \text { (Talley, 2008) }^{2} \\
18(\text { Lumpkin and Speer, 2007) } \\
16(\text { ECCO })^{3}\end{array}$ \\
\hline $\begin{array}{l}M_{\mathrm{S}}(\mathrm{Sv}) \text { : transport at } 32^{\circ} \mathrm{S} \\
\text { above the } 27.4 \text { isopycnal }\end{array}$ & 6.7 & -3.7 & 15.9 & 12.2 & $\begin{array}{l}-1.1 \text { (Talley, 2008) } \\
7.9 \text { (Lumpkin and Speer, 2007) } \\
15.8(\text { ECCO })^{3}\end{array}$ \\
\hline$M_{\mathrm{u}}=M_{\mathrm{n}}-M_{\mathrm{S}}(\mathrm{Sv})$ & 6.9 & 21.6 & 2.5 & 6.6 & $\begin{array}{l}20.1{\text { (Talley, } 2008)^{2}} \\
10.1(\text { Lumpkin and Speer, 2007) } \\
0.2(\text { ECCO })^{3}\end{array}$ \\
\hline
\end{tabular}

1 Averaged from $30^{\circ} \mathrm{S}-40^{\circ} \mathrm{N}$;

${ }^{2}$ Estimated from inverse models at approximately $48^{\circ} \mathrm{N}\left(M_{\mathrm{n}}\right)$ and $32^{\circ} \mathrm{S}\left(M_{\mathrm{S}}\right)$ using hydrographic data; details in Lumpkin and Speer (2007) and Talley (2008).

${ }^{3}$ Maximum global overturning at $48^{\circ} \mathrm{N}$ and $32^{\circ} \mathrm{S}$ calculated from the Ocean Comprehensive Atlas (OCCA), produced at the Massachusetts Institute of Technology (MIT) by the Estimating the Circulation and Climate of the Ocean (ECCO) group. The OCCA Atlas is publicly available (http://www.ecco-group.org/) for the data-rich Argo period from 2004 to 2006 (Forget, 2010). OCCA is an ocean climatology produced by calculating the least squares fit of a global full-depth-ocean and sea-ice configuration of the MIT general circulation model (MITgcm) to satellite and in situ data.
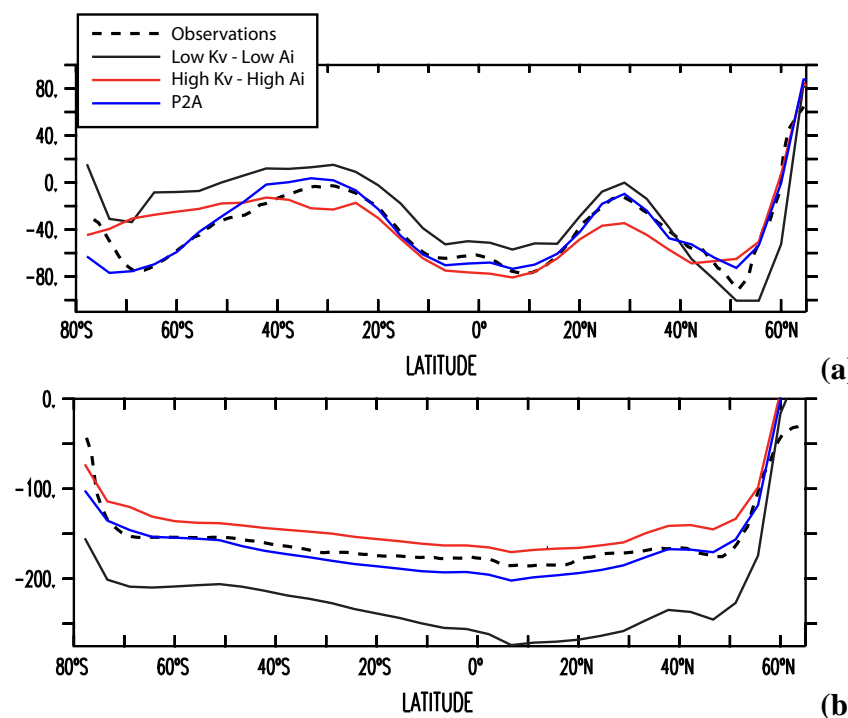

(a)

(b)
Table 3. Percentage contribution of each tagged water mass to the upper ocean volume (above the 26.8 isopycnal) between $30^{\circ} \mathrm{S}$ and $30^{\circ} \mathrm{N}$ in italic lettering. Listed in parentheses are the percentage contributions of unmodified tagged phosphate (first number) and the remineralized tagged phosphate (second number) to the total phosphate inventory above the 26.8 isopycnal. The columnwise sum of the unmodified and remineralized contributions (both numbers in parentheses) should be close to $100 \%$ of the total phosphate reservoir. However, some columns may sum to less than $100 \%$ due to roundoff error and because part of the Bay of Bengal is only partially tagged.

\begin{tabular}{lllll}
\hline & LL & HH & LL-ECMWF & P2A \\
\hline North Atlantic & $5(2,3)$ & $4(1,4)$ & $5(2,2)$ & $6(3,5)$ \\
North Pacific & $24(10,22)$ & $14(5,11)$ & $16(8,16)$ & $15(6,15)$ \\
Deep Low latitude & $8(9,9)$ & $33(22,21)$ & $6(6,7)$ & $5(6,5)$ \\
SAMW & $60(18,21)$ & $45(12,13)$ & $68(26,28)$ & $67(24,24)$ \\
AAIW & $3(2,3)$ & $4(2,4)$ & $3(2,3)$ & $2.5(3,4)$ \\
Southern & $0(0,1)$ & $0(0,2)$ & $0(0,1)$ & $0(1,3)$ \\
\hline
\end{tabular}

Fig. 7. Zonal and depth-average $\delta^{14} \mathrm{C}$ above (a) and below (b) the 27.4 isopycnal for the observations from the GLODAP database (Key et al., 2004) and 3 of the 4 ocean models described in Table 1. The LL-ECMWF model is excluded, because it was not run with $\delta^{14} \mathrm{C}$ as a tracer. 


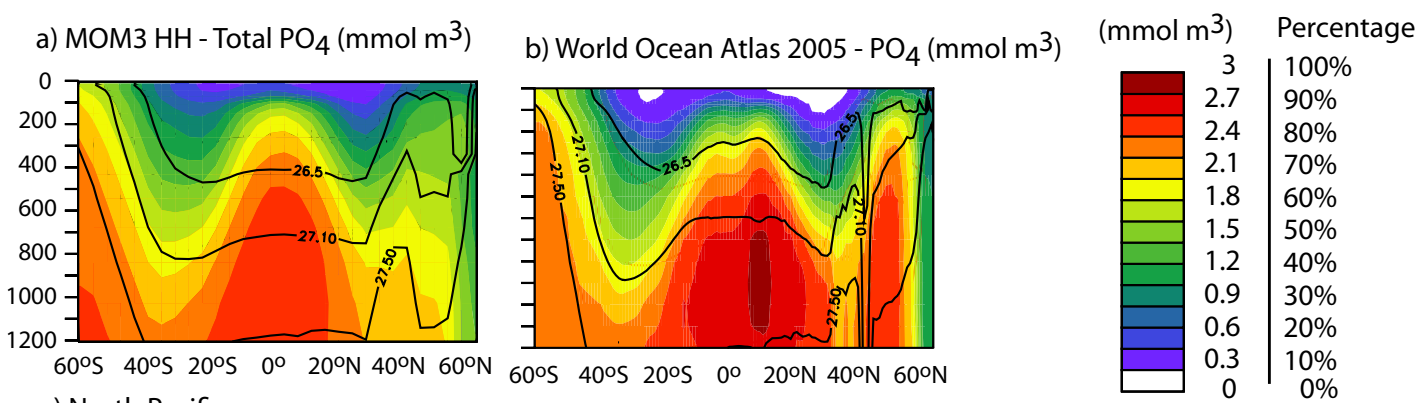

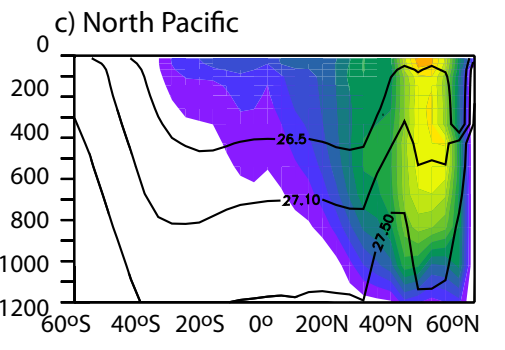

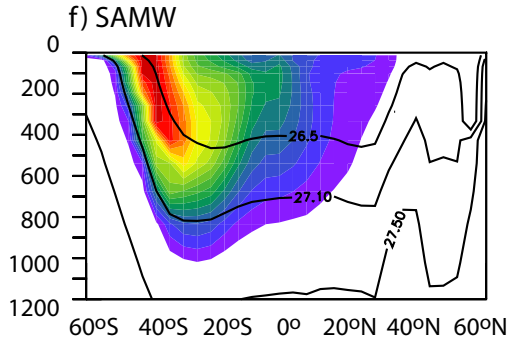

d) North Atlantic

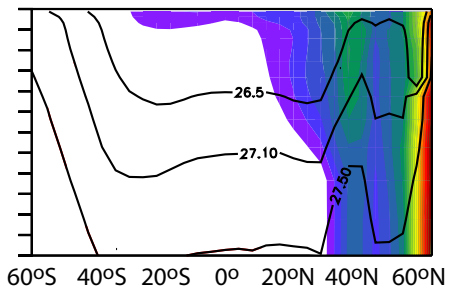
g) AAIW

e) "Tropical deep" $\left(\sigma_{\theta}>27.4\right)$

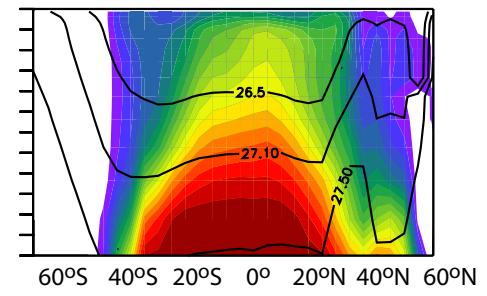

h) South
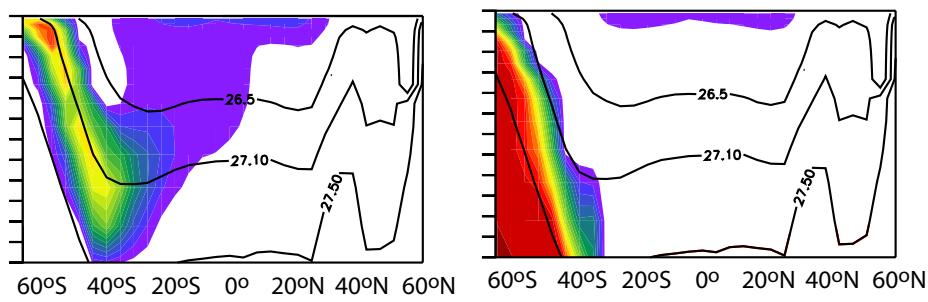

Fig. 8. Zonally-averaged $\mathrm{PO}_{4}^{3-}$ in (a) the $\mathrm{HH}$ model and (b) observations. Panels (c-h) show the percentage of total $\mathrm{PO}_{4}^{3-}$ comprised by each regional phosphate tag in the $\mathrm{HH}$ model, as labeled at the top of each panel. The colorbar applies to all panels, but is in $\mathrm{mmol} \mathrm{m}^{-3}$ for panels $(\mathrm{a}-\mathrm{b})$ and percentage of total $\mathrm{PO}_{4}^{3-}$ for $(\mathrm{c}-\mathrm{h})$.

across the pycnocline. Among the three models with smaller coefficients of vertical mixing, the differences are less stark; still, the SAMW fraction at low latitudes is reduced in the LL model relative to the LL-ECMWF and P2A models, as the latter are forced with stronger Southern Ocean westerly winds (i.e. the ECMWF winds). The water mass fractions obtained from the dye tags and the fraction of low latitude phosphate obtained from the nutrient tags can be quite different (Table 3). For example, in the P2A model, the Deep Low latitude tag contributes only $5 \%$ of the low latitude pycnocline waters, but provides $11 \%$ of its phosphate, whereas the SAMW-tag contributes $67 \%$ of the pycnocline waters but only $48 \%$ of the phosphate (Table 3 ). These differences arise because the phosphate concentration in a tagged water mass may be highly elevated above the phosphate concentration in the pycnocline. Thus, when the water mass is mixed or advected into the pycnocline it can contribute a greater percentage of the resultant phosphate concentration than the corresponding contribution of the dye fraction. Such is the case for the phosphate-enriched deep ocean.

Each of the models demonstrates some skill at reproducing the large-scale features of the nutricline: simulated $\mathrm{PO}_{4}^{3-}$ concentrations arch upward from the deep, depleted bowls of the subtropical gyres to the shallow nutricline of the equator and the high latitudes, just as they do in the observational data (Figs. 8a-b and 9a-b). For brevity, we have chosen to show the zonally-averaged sections only for the $\mathrm{HH}$ and P2A models in Figs. 8 and 9; though $\mathrm{HH}$ is quite different from the other three models, LL, LL-ECMWF, and P2A are qualitatively similar, at least as far as the zonally-averaged nutrient sections are concerned.

The Southern Ocean is notable for its elevated near-surface nutrient concentrations (Figs. 8 and 9), which result from strong vertical and lateral advection and mixing of nutrients to the surface (Sloyan and Rintoul, 2001; Naveira Garabato et al., 2004; Sarmiento et al., 2004) in the presence of weak, iron- and light-limited biological drawdown (Coale et al., 2004). The simplified biogeochemical model from the OCMIP-2 protocol does not simulate an iron cycle, nor does it evaluate the irradiance available for photosynthesis. Nonetheless, the biological model does represent the sluggish biological $\mathrm{PO}_{4}^{3-}$ drawdown in the Southern Ocean that results from iron and light limitation, because it allows productivity to remove surface nutrients only when model $\mathrm{PO}_{4}^{3-}$ concentrations exceed observed climatological mean surface $\mathrm{PO}_{4}^{3-}$ concentrations. Because there are high surface $\mathrm{PO}_{4}^{3-}$ 

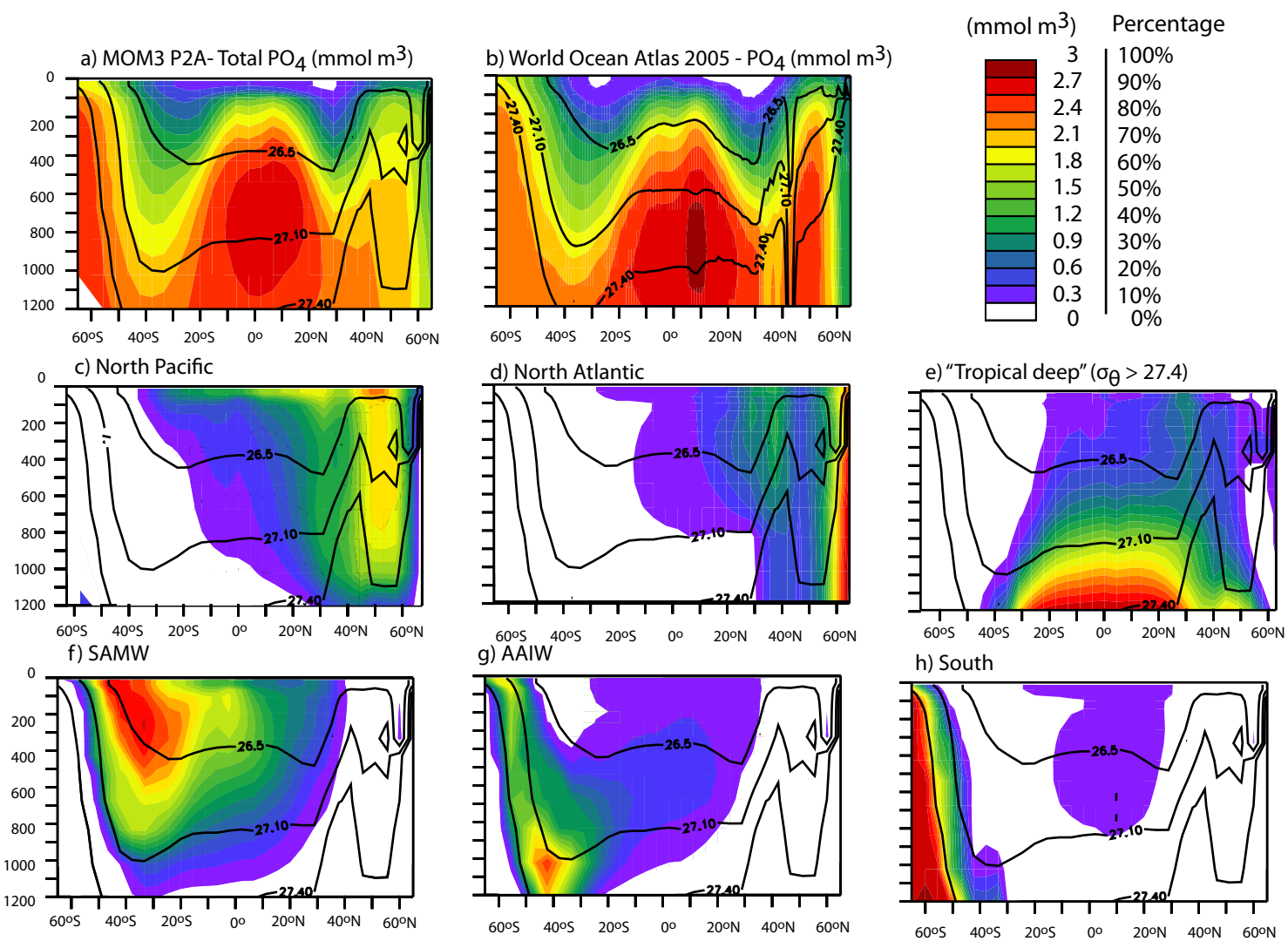

Fig. 9. Same as Fig. 8, but for the P2A model.

concentrations in the Subantarctic Zone where SAMW is formed, the modeled SAMW is subducted with some of the highest preformed nutrient concentrations in the global pycnocline. The high unmodified SAMW phosphate concentrations are determined by the OCMIP biogeochemistry, which sets surface nutrients at their climatological values, and is therefore not sensitive to the differing physics in each model. On the other hand, the degree to which these nutrients spread from the SAMW source region to fuel downstream export production is highly dependent on model physics.

This intermodel difference can clearly be seen in tropical nutrient cycling (Figs. 8 and 9). In the HH model compared to the P2A model, the spreading of the SAMW phosphate is restricted to a narrow band near its source region, largely because the high GM coefficient $\left(A_{i}\right)$ creates a parameterized southward eddy transport that compensates the northward Ekman transport of SAMW (Figs. 8f and 9f). Similarly, this same GM transport causes more restricted spreading of North Pacific phosphate in the $\mathrm{HH}$ run relative to the runs with a lower GM coefficient (Figs. 8c and 9c). Furthermore, the deep low latitude phosphate diffuses strongly across the low latitude pycnocline due to the choice of high diapycnal diffusion (Figs. 8e and 9e). This strong diffusion of nutrients across the low-latitude pycnocline also causes the HH model to have lower concentrations of phosphate in the dense wa- ters underlying the tropics, the highest low-latitude productivity, and the one that disagrees the most with observations (Gnanadesikan et al., 2002).

Winds also affect the extent to which the spreading of the SAMW transports nutrients away from the Southern Ocean (Fig. 10). In the models forced with sluggish Southern Ocean winds (LL and HH), the unmodified SAMW phosphate comprises the majority of the total pycnocline nutrients only in a narrow band south of $30^{\circ} \mathrm{S}$ near the tagging region (Fig. 10) and represents less than $10 \%$ of the nutrients in the Northern Hemisphere gyres. Spreading of the unmodified SAMW phosphate is stronger in the P2A and LL-ECMWF models, contributing up to $20 \%$ of the total $\mathrm{PO}_{4}^{3-}$ above the 26.8 isopycnal in the subtropical North Atlantic (Fig. 10, top row). This density horizon is chosen to represent nominally the base of the ventilated pycnocline, but the qualitative results are not sensitive to the density horizon used, as long as it is above the 27.4 isopycnal below which the deep low latitude tag is assigned. Indeed, the relative rank of each tagged phosphate with regard to its contribution to the low-latitude pycnocline phosphate remains the same when averaging above the 27.3 isopycnal as the 26.8 isopycnal.

The importance of SAMW supply is more apparent in the spreading of its remineralized component (Fig. 10, bottom row). Whereas the unmodified SAMW phosphate is largely 


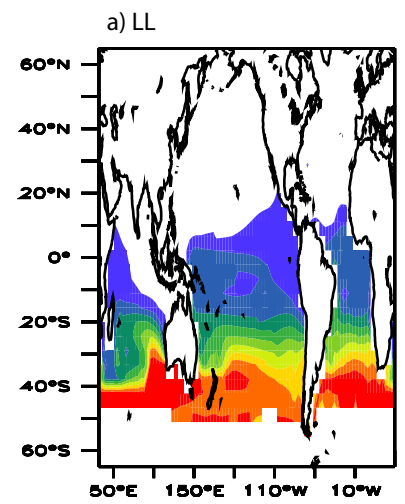

e) LL

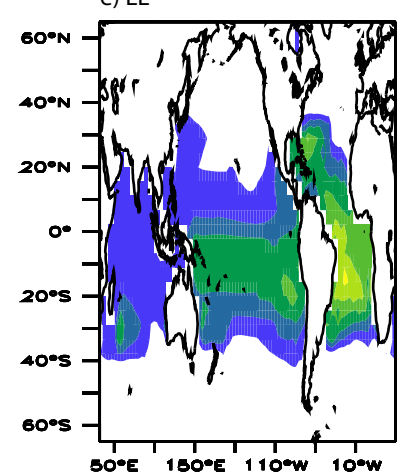

b) $\mathrm{HH}$

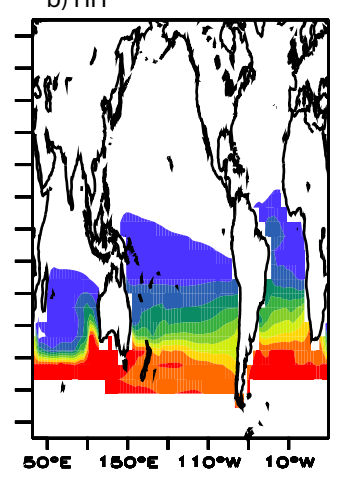

f) $\mathrm{HH}$

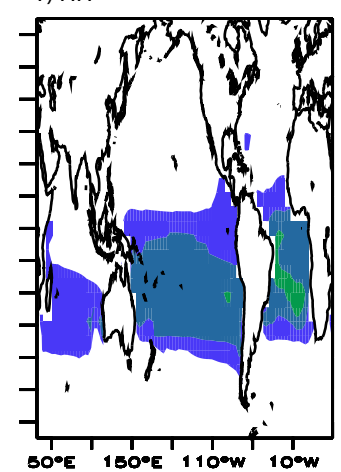

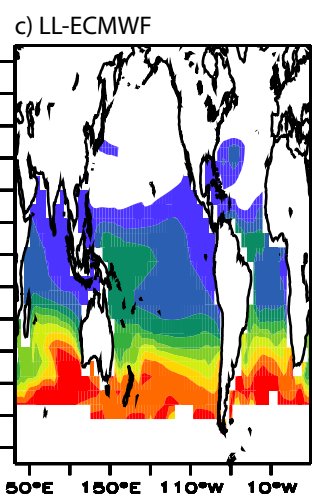

g) LL-ECMWF

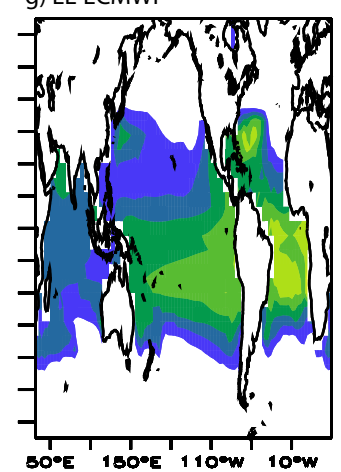

d) $\mathrm{P} 2 \mathrm{~A}$

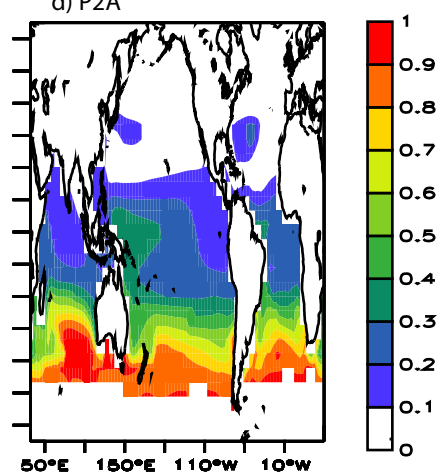

h) $\mathrm{P} 2 \mathrm{~A}$

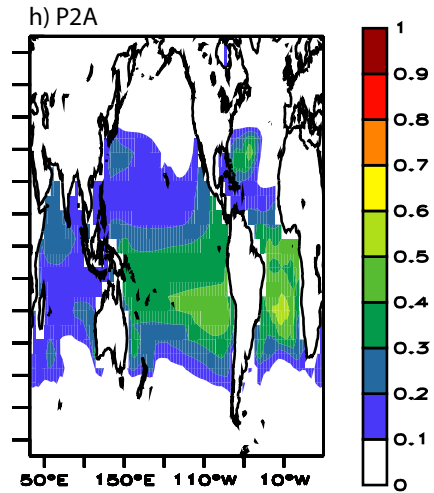

Fig. 10. The fraction of total phosphate above the 26.8 isopycnal comprised by unmodified SAMW phosphate (top panels) and remineralized SAMW phosphate (bottom panels) in the 4 models described in Table 2, as labeled at the top of each map. Unmodified SAMW phosphate is phosphate that comes directly from the tagging region without ever fueling productivity, while remineralized SAMW phosphate derives either from DOP tagged in the SAMW source region and remineralized to phosphate or SAMW phosphate that has fueled export production at least once (see Sect. 2.3 for details).

confined to the Southern Ocean, the remineralized SAMW phosphate can propagate far downstream of its tagging region, contributing a significant phosphate source even in the Northern Hemisphere subtropical gyres (Fig. 10). We estimate a maximum time scale associated with the conversion of preformed to remineralized SAMW phosphate by dividing the total unmodified SAMW phosphate reservoir by the rate of its consumption in fueling primary production. On average across the models, the unmodified SAMW phosphate fuels primary production within 33 years of its creation. The time scale is longest in the P2A model (39 years), which has both a large SAMW unmodified nutrient pool and a weak vertical mixing coefficient outside of the Southern Ocean. The time scale of unmodified SAMW phosphate drawdown is shortest in the HH model (22 years), with its small SAMW pool and higher mixing rates. The designation of unmodified SAMW phosphate is similar to preformed phosphate except where the nutrients that are tagged outside of the mixed layer. Because the unmodified pool is probably somewhat greater than the preformed pool, these estimates of the time scale for the conversion of SAMW nutrients from preformed to remineralized are likely an upper bound.

\subsection{Sustaining low latitude export production}

The nutrients tagged in the SAMW region are the most important source of nutrients sustaining low latitude (nominally $30^{\circ} \mathrm{S}$ to $30^{\circ} \mathrm{N}$ ) export production in every model except $\mathrm{HH}$ (Fig. 11). In the HH model, productivity throughout the low latitudes is sustained primarily by phosphate that upwells directly from the abyss across the low-latitude pycnocline, and secondarily by the SAMW phosphate. The unmodified phosphate of any variety fuels less than $30 \%$ of the total productivity (Fig. 11, right column), and low latitude productivity draws primarily from the remineralized phosphate pool. Therefore, nutrients reaching the euphotic zone from any source region are utilized at least once, if not many times, before entering a new tagging region. In all models but $\mathrm{HH}$, the unmodified SAMW phosphate sustains more export production near the equator and in the low latitudes of the North Atlantic than any other unmodified tagged phosphate pool.

Nutrients that cycle through the North Pacific and North Atlantic support relatively little low latitude productivity (Fig. 11). Their most important contribution is in the northern half of the subtropical North Atlantic and North Pacific. 

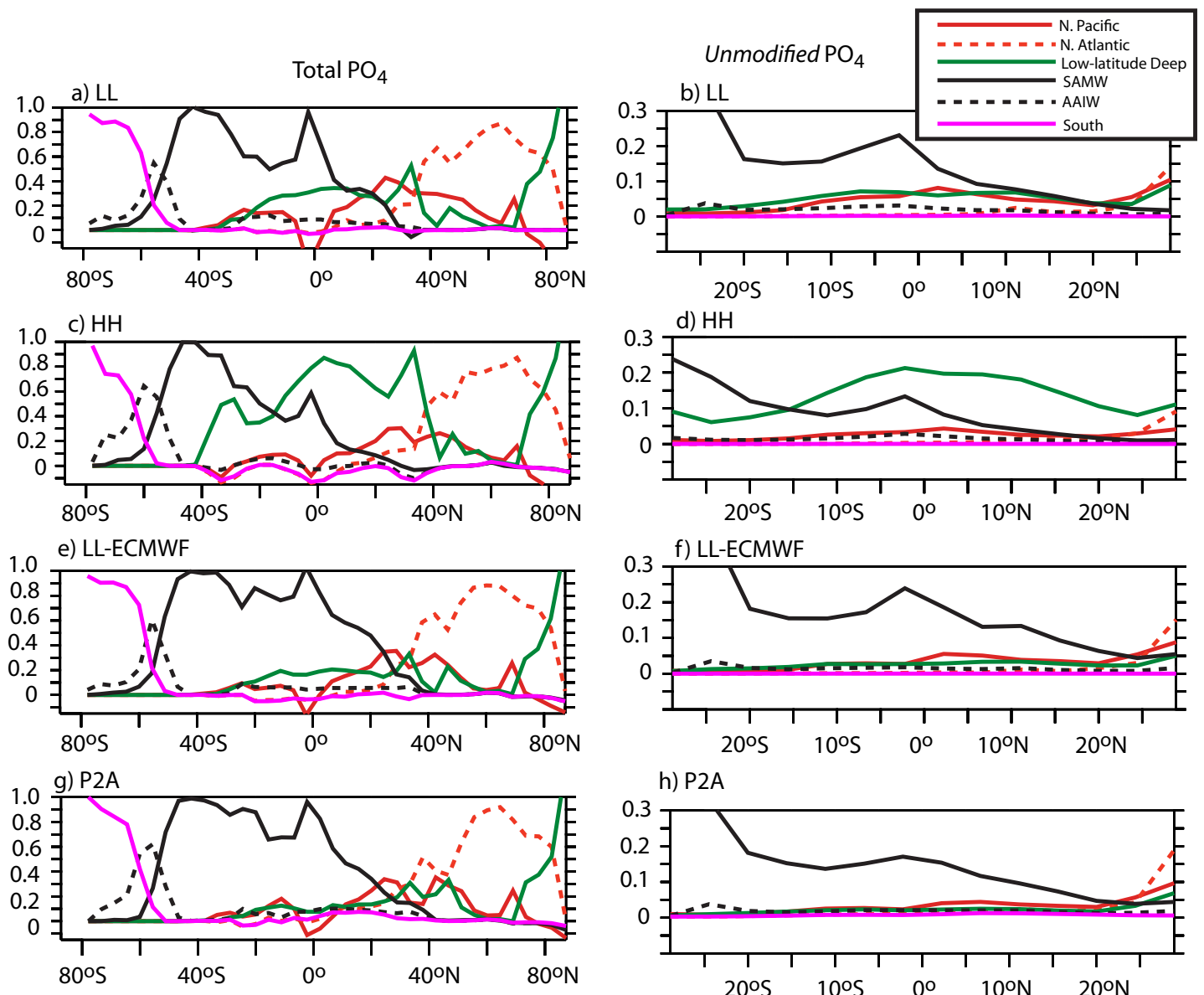

h) $\mathrm{P} 2 \mathrm{~A}$

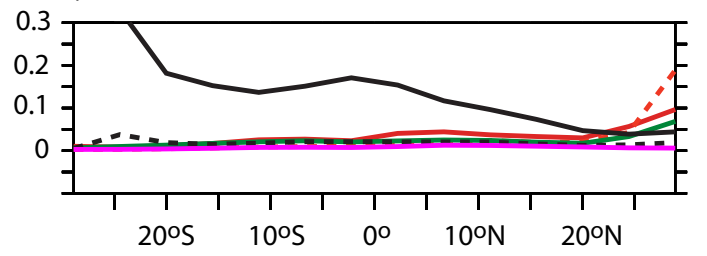

Fig. 11. The zonally-averaged fraction of export production fueled by phosphate (unmodified + remineralized) from each of the tagging regions (left column) and by the unmodified component of each tagged phosphate between $30^{\circ} \mathrm{S}$ and $30^{\circ} \mathrm{N}$ (right column) for the four models described in Table 1. Note the panels on the left show the full latitude range of the model ocean, while the panels on the right show only the low-latitudes. The contribution of the remineralized components of tagged phosphate to sustaining low latitude productivity is the difference between the contributions of the total tagged phosphate (left) and the unmodified component of the tagged phosphate (right). Negative values reflect the method used to diagnose the export production fueled by each tagged nutrient using the source/sink terms for DOP and $\mathrm{PO}_{4}^{3-}$, as described at the end of Sect. 2.3. The lines refer to phosphate from the North Pacific (red solid), North Atlantic (red dotted), Deep low latitude (green solid), SAMW (black solid), AAIW (black dotted), and Southern (magenta solid) regions (refer to Fig. 4 for tagging protocol). Note the different horizontal and vertical scales for the left and right panels.

As the Northern Hemisphere nutrients are advected southward of $40^{\circ} \mathrm{N}$, they are promptly consumed and exported. When the sinking flux of the phosphorus penetrates past the 27.4 isopycnal, it is retagged as deep low latitude phosphate, which limits the number of times the northern-tagged phosphate can fuel productivity via recycling. In addition, a portion of the North Atlantic DOP and phosphate sinks with the deep water and spreads to the deep low latitude tagging region (where the North Atlantic tag is reset to zero) without first fueling productivity.

How do nutrients subducted in the SAMW layer at densities greater than those in the subtropical euphotic zone come to influence productivity in low latitudes? To help answer this question, we examine the vertical flux of the SAMW tag at the depth of the 26.5 isopycnal (Fig. 12), which is regularly ventilated in the subtropical North Atlantic. However, before discussing how the SAMW rises to the shallower isopycnals, we must first address the fact that the tag appears to move downwards at the depth of the 26.5 isopycnal just north of the tagging region. This net downward flux is a consequence of the vertical gradient in SAMW concentrations at the depth of the 26.5 isopycnal just north of the tagging region. In this region, SAMW concentrations decrease with depth across the 26.5 isopycnal because northward transport supplies the tag at the surface while the tagging protocol destroys the tag at depth. The downwelling and vertical diffusion acting on this gradient transport the SAMW tag downward. Downstream of this downwelling domain, the SAMW is transported upwards 
a) $\mathrm{HH}$ - Vertical advection

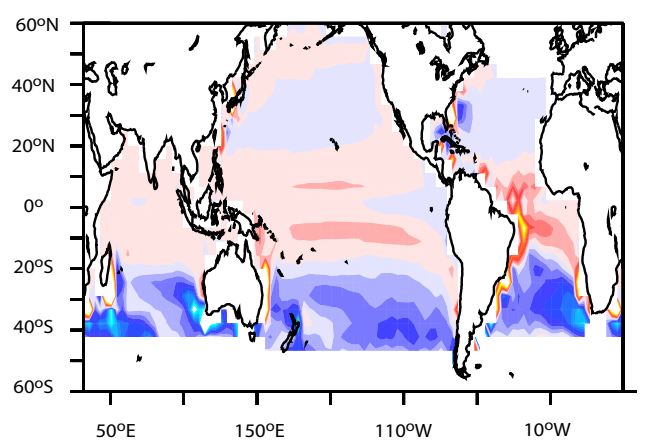

d) P2A - Vertical advection

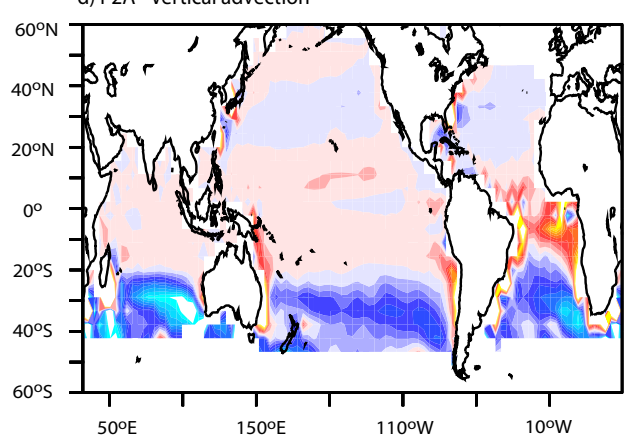

b) $\mathrm{HH}$ - Vertical diffusion

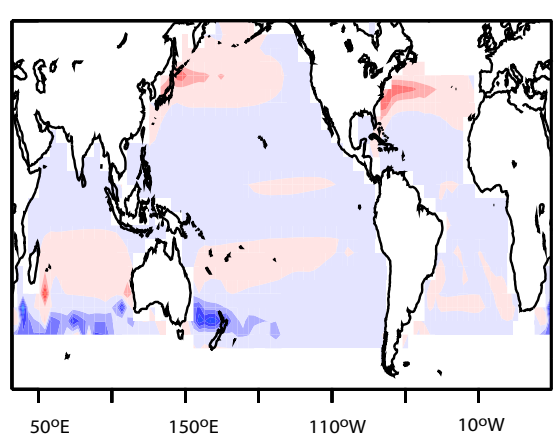

e) P2A - Vertical diffusion

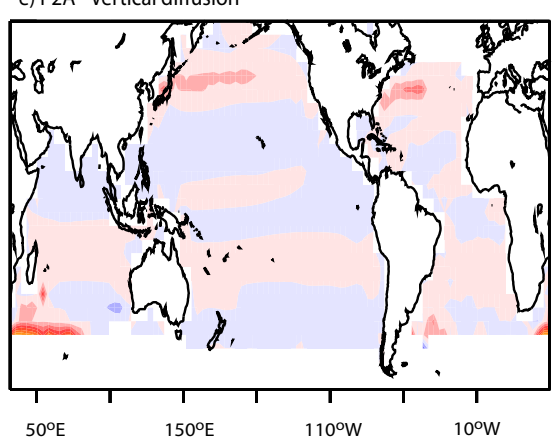

fraction $\mathrm{m}^{-2} \mathrm{~s}^{-1}$
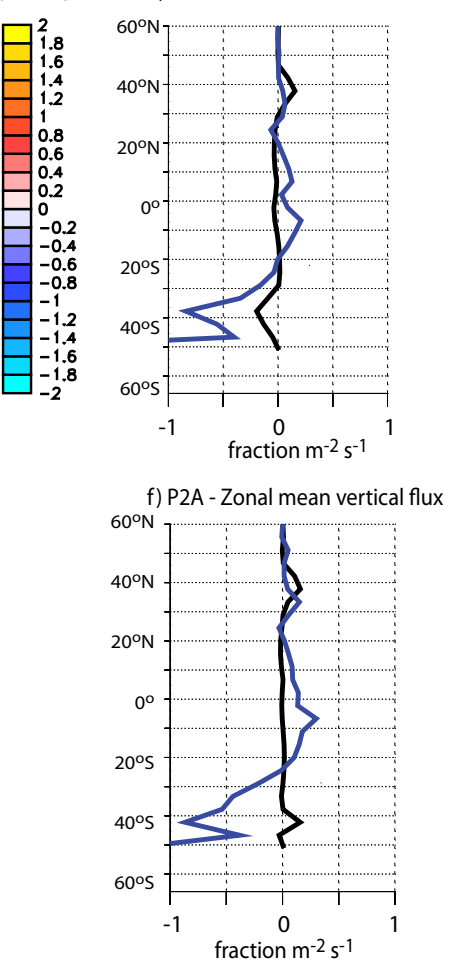

Fig. 12. Vertical fluxes of SAMW dye (in fractional concentration per $\mathrm{m}^{2} \mathrm{~s}$ ) at the depth of the 26.5 isopycnal. Upper row is for the HH model and lower row for P2A. The left hand panels are the vertical advective flux ( $w C$, where $w$ is the vertical velocity and $C$ is the concentration of the SAMW dye tag). The right hand panels are the vertical diffusive flux ( $\kappa_{\mathrm{V}} \mathrm{d} C / \mathrm{d} z$, where $\kappa_{\mathrm{V}}$ is the coefficient of diapycnal diffusion). The diffusive flux includes mixing due to convection and stirring due to the GM transport. The colorbar to the right of panel (b) applies to all maps, and positive numbers represent an upwards flux. The line plots are the zonal means of the maps (black for vertical advection and blue for vertical diffusion).

at the depth of the 26.5 isopycnal. The upward transport is primarily achieved by vertical advection in tropical regions, along the eastern fringes of the Southern Hemisphere subtropical basins, and in the South Atlantic western boundary current off Brazil (Fig. 12).

Once it has been advected and mixed to shallower depths, the SAMW is transformed by surface buoyancy forcing and diapycnal mixing and may no longer carry the characteristic temperature, salinity and potential vorticity signature it had upon formation and subduction. However, our tags trace the water mass fraction and its nutrients downstream of the tagging regions even as the water mass itself is destroyed by such transformations. The SAMW nutrients that are upwelled into the euphotic zone in the tropics and along the eastern boundaries of the subtropics are consumed and converted to organic particles that sink through the water column. These sinking particles are partially remineralized on layers with lighter densities and shallower depths than the SAMW had upon subduction (Toggweiler and Carson, 1995; Williams et al., 2006). Thus, a portion of the nutrients originally subducted in the SAMW remains available to support subtropical productivity as it spreads along these lighter surfaces to the neighboring subtropical gyres.
Our model results suggest that nutrients slowly lost to depths beneath the pycnocline throughout the low latitudes return to lighter layers primarily in the Southern Ocean. This picture emerges from all models but $\mathrm{HH}$ and is summarized in Fig. 13. In the Southern Ocean where biological export does not efficiently compete with the advection and mixing of nutrients to the surface layers, nutrients are upwelled and mixed vertically in the ACC and then subducted in the SAMW. Therefore, the water masses formed in the Southern Ocean enter the ocean interior with elevated nutrient concentrations. Although much of these nutrients are subducted to depths well below the subtropical euphotic zone, their upwelling along the eastern and western fringes of the subtropics and in the tropics allows these nutrients to sustain subtropical export production.

Not far from the SAMW source region, the SAMW unmodified nutrients are consumed and converted to their remineralized counterparts within the pycnocline; further downstream the remineralized nutrients are re-incorporated into organic matter wherever they are mixed and advected into the sunlit surface ocean. In these downstream locales, the slow leakage of organic phosphorus past the base of the seasonally-accessible layers is almost entirely balanced by 


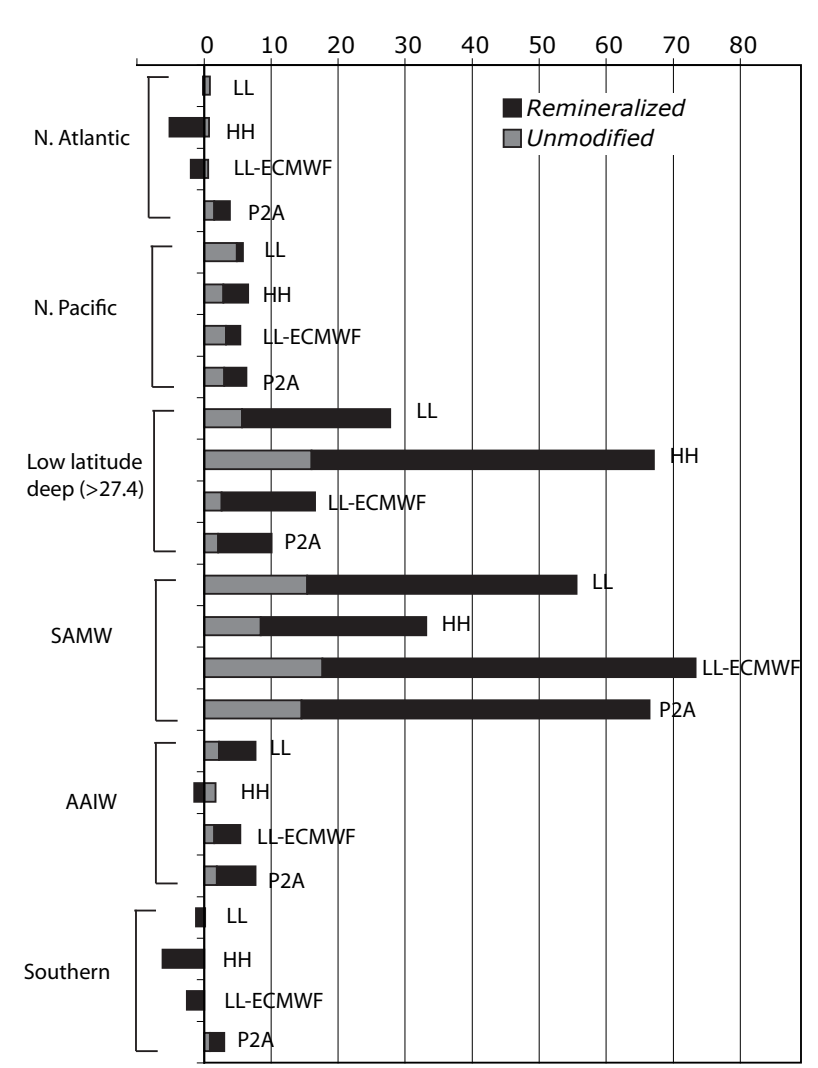

Fig. 13. Percentage of low latitude $\left(30^{\circ} \mathrm{S}-30^{\circ} \mathrm{N}\right)$ export production fueled by nutrients from different tagged regions, separated by unmodified and remineralized components and by model configuration. The salient feature of the graph is that a majority $(57-75 \%)$ of low latitude productivity is sustained by SAMW nutrients, except in the HH model configuration (33\%). Approximately a third of the SAMW nutrients sustaining low latitude productivity are from the unmodified pool, which resemble preformed nutrients when the tags are deployed in the surface mixed layer. Negative values for remineralized tags indicate that unmodified DOP tagged in a given source region is respired to phosphate at a greater rate than the remineralized $\mathrm{PO}_{4}^{3-}$ fuels export production. Such is the case for almost all of the Southern DOP and much of the North Atlantic DOP.

the lateral and vertical supply of nutrients that were cycled through Southern Ocean water masses. In the HH model, the nutrient budget achieves a slightly more one-dimensional balance: a majority of the sinking flux of nutrients downward across the low latitude pycnocline is restored locally via the mixing of nutrients upwards across the low latitude pycnocline. However, even in the HH model, SAMW phosphate sustains more than a third of low latitude productivity; in the other models the percentage is between $57 \%$ and $75 \%$ (Fig. 13). Each of the other tagging regions besides SAMW and deep low latitude contributes less than $10 \%$ of the phosphate that fuels global low latitude export productivity. There is currently no consensus on where and by what mechanisms the upwelling branch of the MOC is achieved: the distributions of tracers such as $\delta^{14} \mathrm{C}$ are consistent with upwelling predominantly in the Southern Ocean (Fig. 7) as are the low coefficients of diapycnal diffusion measured in the ocean interior (Gregg and Sanford, 1980; Ledwell et al., 1993, 1998), while some observationally-based inverse models of overturning suggest a greater role for upwelling at low latitudes (Table 2). This controversy is the motivation for including 4 different models in this analysis, and the range of our results is thought to span the envelope of likely possibilities for the nutrient return pathways occurring in nature.

\section{Conclusions, implications, and connections}

Our model framework has allowed us to identify the dominant nutrient return pathways from the dense ocean interior to depths that are accessible to the sunlit euphotic zone. Between $30^{\circ} \mathrm{S}$ and $30^{\circ} \mathrm{N}$, the upper ocean nutrient reservoir is dominated by those nutrients that were returned from the deep ocean to the pycnocline in the SAMW formation/subduction region of the Southern Ocean (Fig. 13). Only in the model where the coefficient of vertical mixing is set to levels higher than those observed in the pycnocline of the open ocean does mixing directly across the low latitude nutricline provide the dominant return pathway of nutrients to the low latitude euphotic zone. The Northern Hemisphere subpolar regions are not the primary suppliers of nutrients to the low latitude euphotic zones; nor are the regions of Southern Ocean south of the SAMW formation region.

These results are in line with previous modeling studies (Marinov et al., 2006) and with inferences from the distribution of tracers such as $\mathrm{Si}^{*}$ (Sarmiento et al., 2004). But there are two major new insights afforded by this study. The first stems from our focus on the sensitivity of nutrient pathways to the winds, vertical mixing, and the strength of lateral eddy transport (via changes in the GM coefficient). Our results suggest that in models with high vertical mixing, high eddy transport, and low Southern Ocean winds, the dominant nutrient balance is more one-dimensional, i.e. organic nutrients lost by downward sinking at low latitudes are restored through the upward mixing of inorganic nutrients across the pycnocline at these latitudes. At the other extreme, in models with low vertical mixing, weak GM transport, and stronger Southern Ocean winds, organic nutrients lost across the low latitude pycnocline are restored to the pycnocline primarily in the Southern Ocean and depend on the full threedimensional ocean circulation for their delivery to the low latitude euphotic zone.

The second major insight afforded by the study is an approximation of the spatial and temporal scale over which nutrients that enter the ocean interior in the SAMW formation region persist before being utilized in downstream locations. In less than 40 years on average, phosphate entering the ocean interior in the SAMW region is utilized to fuel downstream productivity. In large part, the SAMW nutrients first fuel primary production south of $20^{\circ} \mathrm{S}$. This short spatial 
and temporal scale separating the subduction of SAMW nutrients and their downstream utilization helps explain previous modeling results that tested the influence of the SAMW region on atmospheric carbon concentrations. In the modeling study of Marinov et al. (2006), the SAMW nutrient source was "turned off" by forcing nutrients towards zero at the Southern Ocean surface north of the outcropping 27.3 isopycnal, the equivalent of increasing nutrient drawdown by enhanced export production. Although this forced drawdown decimated low latitude productivity by starving these regions of their nutrients, the experiment had little impact on ocean carbon storage or atmospheric carbon concentrations on millenial time scales. The reason for the lack of impact on atmospheric carbon is that the biological pump had been made much more efficient locally in the SAMW formation region, but the global efficiency was unchanged once the model returned to equilibrium (Marinov et al., 2006). In experiments without the forced nutrient drawdown, the SAMW nutrients were already being efficiently consumed downstream of the SAMW formation region on decadal time scales.

Our model experiments suggest a paradigm for returning nutrients to the surface ocean that contextualizes a number of phenomena. For example, it has been hypothesized that biological nitrogen fixation in the North Atlantic is sustained by excess phosphate (phosphate in excess of nitrate relative to their Redfield ratio) advected in the shallow limb of the MOC (Moore et al., 2009). The excess phosphate signature in the shallow MOC layers stems from the SAMW formation region, where high-phosphate waters from the Indo-Pacific Basin are mixed with the water masses advected across the ACC. Iron limits biological nitrogen fixation in the SAMW formation region and throughout the subtropical South Atlantic, so the excess phosphate signature is preserved during formation and subduction and is exported to the North Atlantic. Because nitrogen fixation in the relatively ironrich North Atlantic appears to be phosphate-limited (SañudoWilhelmy et al., 2001; Moore et al., 2009), the SAMW excess phosphate source may exert an important control on the rate of nitrogen fixation. Such a dependence implies a central role for the export of SAMW in the shallow limb of the MOC.

The framework suggested by the modeling experiments also provides a context for results from a recent paleoclimatology study (Anderson et al., 2009). Anderson et al. (2009) hypothesize that the termination of the last ice age was linked to an increase in Southern Ocean upwelling and the resultant efflux of carbon from the deep ocean to the atmosphere. The primary evidence used to support this hypothesis is the enhanced burial of biogenic opal in the Southern Ocean and equatorial Pacific, which occurred contemporaneously with the increase in atmospheric $\mathrm{CO}_{2}$ and the onset of deglaciation. The hypothesized mechanism is an increase in Southern Ocean upwelling, which brings deep carbon to the surface ocean south of the ACC with the upwelling of Circumpolar Deep Water and also advects a pulse of silicic acid across the
ACC into the SAMW formation region. As the carbon outgases south of the ACC and enters the atmosphere to warm the planet, the silicic acid flux fuels a diatom bloom in the SAMW formation region and - contemporaneously by geological standards - in the equatorial Pacific. The inference from our model experiments that Southern Ocean nutrients fuel a large portion of low latitude productivity and are consumed on decadal time scales offers a framework for understanding this paleo-record.

Having summarized the major insights of our model experiments and explored their connections with recent work, we recognize a list of challenges that await future study. First, for a clearer picture of the preformed nutrient content of the interior ocean, it would be helpful to separate nutrients that cycle through the surface mixed layer during water mass formation and those that enter water masses via interior mixing and sinking. Second, the MOM3 suite is a set of coarseresolution models that depend on parameterizations for all mesoscale dynamics and are known to yield qualitatively and quantitatively different results when compared to eddyresolving models (e.g. Hallberg and Gnanadesikan, 2006). Thus, work with eddy-resolving models should reveal different dynamics and possibly lead to different pathways for nutrients. Third, our models are configured with one vertical mixing profile for the global ocean, which was altered only in P2A in order to simulate higher Southern Ocean mixing. Such uniformity in mixing does not capture the observed enhancement of mixing in regions of rough topography, such as tidal mixing (St. Laurent and Simmons, 2006) which is parameterized in more recent GCMs (Simmons et al., 2004). Finally, the OCMIP-2 biology is not fully prognostic because it is forced towards observations at the surface. Thus, the models cannot represent changes to biology at the surface forced by the models' differing physics, a challenge that can be tackled with fully prognostic biological models. Future efforts could also move beyond our steady state solution and address temporal variability at time scales other than seasonal, incorporate ocean-atmosphere coupling, and examine the hypothesized alterations in the nutrient return pathways under different climate scenarios.

Acknowledgements. The authors are thankful for helpful comments from Robbie Toggweiler, Stephanie Downes, Andreas Oschlies, and an anonymous reviewer. The authors acknowledge support from the NOAA-Cooperative Institute for Climate Science Grant \#NA08OAR4320752; the National Oceanic and Atmospheric Administration, US Department of Commerce award NA07OAR4310096; and the Office of Science (BER), US Department of Energy, Grant No. DE-FG02-07ER64467. All statements, findings, conclusions, and recommendations are those of the authors and do not necessarily reflect the views of the National Oceanic and Atmospheric Administration, the US Department of Commerce, or the US Department of Energy.

Edited by: G. Herndl 


\section{References}

Anderson, R. F., Ali, S., Bradtmiller, L. I., Nielsen, S. H. H., Fleisher, M. Q., Anderson, B. E., and Burckle, L. H.: Wind-Driven Upwelling in the Southern Ocean and the Deglacial Rise in Atmospheric $\mathrm{CO}_{2}$, Science, 323, 1443-1448, doi:10.1126/science.1167441, 2009.

Archer, D. E., Eshel, G., Winguth, A., Broecker, W., Pierrehumbert, R., Tobis, M., and Jacob, R.: Atmospheric $p \mathrm{CO}_{2}$ sensitivity to the biological pump in the ocean, Global Biogeochem. Cy., 14, 1219-1230, 2000.

Cao, L., Eby, M., Ridgwell, A., Caldeira, K., Archer, D., Ishida, A., Joos, F., Matsumoto, K., Mikolajewicz, U., Mouchet, A., Orr, J. C., Plattner, G.-K., Schlitzer, R., Tokos, K., Totterdell, I., Tschumi, T., Yamanaka, Y., and Yool, A.: The role of ocean transport in the uptake of anthropogenic $\mathrm{CO}_{2}$, Biogeosciences, 6, 375-390, doi:10.5194/bg-6-375-2009, 2009.

Coale, K. H., Johnson, K. S., Chavez, F. P., Buesseler, K. O., Barber, R. T., Brzezinski, M. A., Cochlan, W. P., Millero, F. J., Falkowski, P. G., Bauer, J. E., Wanninkhof, R. H., Kudela, R. M., Altabet, M. A., Hales, B. E., Takahashi, T., Landry, M. R., Bidigare, R. R., Wang, X., Chase, Z., Strutton, P. G., Friederich, G. E., Gorbunov, M. Y., Lance, V. P., Hilting, A. K., Hiscock, M. R., Demarest, M., Hiscock, W. T., Sullivan, K. F., Tanner, S. J., Gordon, R. M., Hunter, C. N., Elrod, V. A., Fitzwater, S. E., Jones, J. L., Tozzi, S., Koblizek, M., Roberts, A. E., Herndon, J., Brewster, J., Ladizinsky, N., Smith, G., Cooper, D., Timothy, D., Brown, S. L., Selph, K. E., Sheridan, C. C., Twining, B. S., and Johnson, Z. I.: Southern Ocean Iron Enrichment Experiment: Carbon Cycling in High- and Low-Si Waters, Science, 304, 408-414, doi:10.1126/science.1089778, 2004.

Conkright, M. E., Locarnini, R. A., Garcia, H. E., O’brien, T. D., Boyer, T. P., Stephens, C., and Antonov, J. I.: World Ocean Atlas 2001: Objective Analyses, Data Statistics, and Figures, National Oceanographic Data Center, Silver Spring, MD, 17 pp., 2001.

Cunningham, S. A., Alderson, S. G., King, B. A., and Brandon, M. A.: Transport and variability of the Antarctic Circumpolar Current in Drake Passage, J. Geophys. Res., 108, 8084, doi:10.1029/2001jc001147, 2003.

Da Silva, A., Young, A. C., and Levitus, S.: Atlas of surface marine data 1994, National Oceanic and Atmospheric Administration, Silver Spring, MD, 1994.

de Boyer Montégut, C., Madec, G., Fischer, A. S., Lazar, A., and Iudicone, D.: Mixed layer depth over the global ocean: An examination of profile data and a profile-based climatology, J. Geophys. Res., 109, C12003, doi:10.1029/2004jc002378, 2004.

Dunne, J. P., Sarmiento, J. L., and Gnanadesikan, A.: A synthesis of global particle export from the surface ocean and cycling through the ocean interior and on the seafloor, Global Biogeochem. Cy., 21, GB4006, doi:10.1029/2006GB002907, 2007.

Forget, G.: Mapping ocean observations in a dynamical framework: a 2004-2006 ocean atlas, J. Phys. Oceanogr., 40, 1201-1221, 2010.

Gent, P. R. and McWilliams, J. C.: Isopycnal mixing in ocean circulation models, J. Phys. Oceanogr., 20, 150-155, 1990.

Gnanadesikan, A.: A Simple Predictive Model for the Structure of the Oceanic Pycnocline, Science, 283, 2077-2079, doi:10.1126/science.283.5410.2077, 1999.

Gnanadesikan, A., Slater, R. D., Gruber, N., and Sarmiento, J. L.: Oceanic vertical exchange and new production: a comparison between models and observations, Deep-Sea Res. Pt. II, 49, $363-$ 401, 2002.

Gnanadesikan, A., Dunne, J. P., Key, R. M., Matsumoto, K., Sarmiento, J. L., Slater, R. D., and Swathi, P. S.: Oceanic ventilation and biogeochemical cycling: Understanding the physical mechanisms that produce realistic distributions of tracers and productivity, Global Biogeochem. Cy., 18, 1-17, 2004.

Gnanadesikan, A., De Boer, A. M., and Mignone, B. K.: A simple theory of the pycnocline and overturning - revisited, Ocean Circulation: Mechanisms and Impacts, Geoph. Monog. Series, 173, 335-349, 2007.

Gnanadesikan, A. and Marinov, I.: Export is not enough: nutrient cycling and carbon sequestration, Mar. Ecol.-Prog. Ser., 364, 289-294, doi:10.3354/meps07550, 2008.

Gregg, M. C. and Sanford, T. B.: Signatures of mixing from the Bermuda Slope, the Sargasso Sea and the Gulf Stream, J. Phys. Oceanogr., 10, 105-127, 1980.

Hallberg, R. and Gnanadesikan, A.: The Role of Eddies in Determining the Structure and Response of the Wind-Driven Southern Hemisphere Overturning: Results from the Modeling Eddies in the Southern Ocean (MESO) Project, J. Phys. Oceanogr., 36, 2232-2252, 2006.

Hanawa, K. and Talley, L.: Mode Waters, in: Ocean Circulation and Climate, edited by: Siedler, G. and Church, J., International Geophysics Series, Academic Press, 373-386, 2001.

Hellerman, S. and Rosenstein, M.: Normal monthly wind stress over the world ocean with error estimates, J. Phys. Oceanogr., 13, 1093-1104, 1983.

Heywood, K. J., Naveira Garabato, A. C., and Stevens, D. P.: High mixing rates in the abyssal Southern Ocean, Nature, 415, 10111014, 2002.

Ito, T. and Follows, M. J.: Preformed phosphate, soft tissue pump and atmospheric $\mathrm{CO}_{2}$, J. Mar. Res., 63, 813-839, 2005.

Karsten, R. H. and Marshall, J.: Constructing the Residual Circulation of the ACC from Observations, J. Phys. Oceanogr., 32, 3315-3327, 2002.

Key, R. M., Kozyr, A., Sabine, C., Lee, K., Wanninkhof, R., Bullister, J. L., Feely, R. A., Millero, F. J., Mordy, C., and Peng, T.-H.: A global ocean carbon climatology: Results from GLODAP, Global Biogeochem. Cy., 18(4), GB4031, doi:10.1029/2004gb002247, 2004.

Kuhlbrodt, T., Griesel, A., Montoya, M., Levermann, A., Hoffman, M., and Rahmstorf, S.: On the driving processes of the Atlantic Meridional Overturning Circulation, Rev. Geophys., 45, RG2001, doi:10.1029/2004rg000166, 2007.

Le Quéré, C., Rödenbeck, C., Buitenhuis, E. T., Conway, T. J., Langenfelds, R., Gomez, A., Labuschagne, C., Ramonet, M., Nakazawa, T., Metzl, N., Gillett, N., and Heimann, M.: Saturation of the southern ocean $\mathrm{CO}_{2}$ sink due to recent climate change, Science, 316, 1735-1738, 2007.

Ledwell, J. R., Watson, A. J., and Law, C. S.: Evidence for slow mixing across the pycnocline from an open-ocean tracer-release experiment, Nature, 364, 701-703, 1993.

Ledwell, J. R., Watson, A. J., and Law, C. S.: Mixing of a tracer in the pycnocline, J. Geophys. Res., 103, 21499-21529, 1998.

Levitus, S., Burgett, R., and Boyer, T. P.: World Ocean Atlas, NOAA Atlass NESDIS 3, National Oceanic and Atmospheric Administration, Silver Spring, MD, 1994.

Louanchi, F. and Najjar, R. G.: A global monthly climatology 
of phosphate, nitrate and silicate in the upper ocean: Springsummer export production and shallow remineralization, Global Biogeochem. Cy., 14, 957-977, 2000.

Lumpkin, R. and Speer, K.: Global Ocean Meridional Overturning, J. Phys. Oceanogr., 37, 2550-2562, 2007.

Marinov, I., Gnanadesikan, A., Toggweiler, J. R., and Sarmiento, J. L.: The Southern Ocean biogeochemical divide, Nature, 441, 964-967, 2006.

Marinov, I., Follows, M. J., Gnanadesikan, A., Sarmiento, J. L., and Slater, R. D.: How does ocean biology affect atmospheric $p \mathrm{CO}_{2}$ ? Theory and models, J. Geophys. Res.-Oceans, 113, C07032, doi:10.1029/2007JC004598, 2008a.

Marinov, I., Gnanadesikan, A., Sarmiento, J. L., Toggweiler, J. R., Follows, M., and Mignone, B. K.: Impact of oceanic circulation on biological carbon storage in the ocean and atmospheric $p \mathrm{CO}_{2}$, Global Biogeochemical Cy., 22, GB3007, doi:10.1029/2007GB002958, 2008b.

Matsumoto, K., Sarmiento, J. L., Key, R. M., Aumont, O., Bullister, J. L., Caldeira, K., Campin, J. M., Doney, S. C., Drange, H., Dutay, J. C., Follows, M., Gao, Y., Gnanadesikan, A., Gruber, N., Ishida, A., Joos, F., Lindsay, K., Maier-Reimer, E., Marshall, J. C., Matear, R. J., Monfray, P., Mouchet, A., Najjar, R., Plattner, G. K., Schlitzer, R., Slater, R., Swathi, P. S., Totterdell, I. J., Weirig, M. F., Yamanaka, Y., Yool, A., and Orr, J. C.: Evaluation of ocean carbon cycle models with data-based metrics, Geophys. Res. Lett., 31, L07303, doi:10.1029/2003GL018970, 2004.

McCartney, M. S.: The subtropical recirculation of Mode Waters, J. Mar. Res., 40, 427-464, 1982.

Mignone, B. K., Gnanadesikan, A., Sarmiento, J. L., and Slater, R. D.: Central role of Southern Hemisphere winds and eddies in modulating the oceanic uptake of anthropogenic carbon, Geophys. Res. Lett., 33, L01604, doi:10.1029/2005GL024464, 2006.

Moore, C. M., Mills, M. M., Achterberg, E. P., Geider, R. J., Laroche, J., Lucas, M. I., McDonagh, E. L., Pan, X., Poulton, A. J., Rijkenberg, M. J. A., Suggett, D. J., Ussher, S. J., and Woodward, E. M. S.: Large-scale distribution of Atlantic nitrogen fixation controlled by iron availability, Nat. Geosci., 2, 867-871, 2009.

Munk, W. and Wunsch, C.: Abyssal recipes II: Energetics of tidal and wind mixing, Deep-Sea Res. Pt. I, 45, 1977-2010, 1998.

Najjar, R. G., Jin, X., Louanchi, F., Aumont, O., Caldeira, K., Doney, S. C., Dutay, J. C., Follows, M., Gruber, N., Joos, F., Lindsay, K., Maier-Reimer, E., Matear, R. J., Matsumoto, K., Monfray, P., Mouchet, A., Orr, J. C., Plattner, G. K., Sarmiento, J. L., Schlitzer, R., Slater, R. D., Weirig, M. F., Yamanaka, Y., and Yool, A.: Impact of circulation on export production, dissolved organic matter, and dissolved oxygen in the ocean: Results from Phase II of the Ocean Carbon-cycle Model Intercomparison Project (OCMIP-2), Global Biogeochem. Cy., 21, GB3007, doi:10.1029/2006GB002857, 2007.

Naveira Garabato, A. C., Polzin, K. L., King, B. A., Heywood, K. J., and Visbeck, M.: Widespread Intense Turbulent Mixing in the Southern Ocean, Science, 303, 210-213, 2004.

Pacanowski, R. C. and Griffies, S. M.: The MOM3 manual, Alpha version, Geophysical Fluid Dynamics Laboratory, Princeton, NJ, 580 pp., 1999.

Palter, J. B., Lozier, M. S., and Barber, R. T.: The effect of advection on the nutrient reservoir in the North Atlantic subtropical gyre, Nature, 437, 687-692, 2005.
Polzin, K. L.: A rough recipe for the energy balance of quasi-steady internal lee waves, 'Aha Huliko'a: Dynamics of oceanic internal gravity waves II., Hawaii, 117-128, 1999.

Ridgway, K. R., Dunn, J. R., and Wilkin, J. L.: Ocean Interpolation by Four-Dimensional Weighted Least Squares-Application to the Waters around Australasia, J. Atmos. Ocean. Tech., 19, 13571375, 2002.

Samelson, R. M.: Simple mechanistic models of middepth meridional overturning, J. Phys. Oceanogr., 34, 2096-2103, 2004.

Samelson, R. M.: A simple dynamical model of the warm-water branch of the middepth meridional overturning cell, J. Phys. Oceanogr., 39, 1216-1230, 2009.

Sañudo-Wilhelmy, S. A., Kustka, A. B., Gobler, C. J., Hutchins, D. A., Yang, M., Lwiza, K., Burns, J., Capone, D. G., Raven, J. A., and Carpenter, E. J.: Phosphorus limitation of nitrogen fixation by Trichodesmium in the central Atlantic Ocean, Nature, 411, 66-69, 2001.

Sarmiento, J. L., Gruber, N., Brzezinski, M. A., and Dunne, J. P.: High-latitude controls of thermocline nutrients and low latitude biological productivity, Nature, 427, 56-60, 2004.

Sarmiento, J. L., Simeon, J., Gnanadesikan, A., Gruber, N., Key, R. M., and Schlitzer, R.: Deep ocean biogeochemistry of silicic acid and nitrate, Global Biogeochem. Cy., 21, GB1S90, doi:10.1029/2006gb002720, 2007.

Simmons, H. L., Jayne, S. R., Laurent, L. C. S., and Weaver, A. J.: Tidally driven mixing in a numerical model of the ocean general circulation, Ocean Model., 6, 245-263, 2004.

Sloyan, B. M. and Rintoul, S. R.: Circulation, renewal, and modification of Antarctic mode and intermediate water, J. Phys. Oceanogr., 31, 1005-1030, 2001.

Sloyan, B. M. and Kamenkovich, I. V.: Simulation of Subantarctic Mode and Antarctic Intermediate Waters in Climate Models, J. Climate, 20, 5061-5080, 2007.

St. Laurent, L. and Simmons, H.: Estimates of Power Consumed by Mixing in the Ocean Interior, J. Climate, 19, 4877-4890, 2006.

Stommel, H. and Arons, A. B.: On the abyssal circulation of the world ocean - I. Stationary planetary flow patterns on a sphere, Deep-Sea Res., 6, 140-154, 1961.

Talley, L.: An Okhotsk Sea water anomaly: Implications for ventilation in the North Pacific, Deep-Sea Res., 38, S171-S190, 1991.

Talley, L. D.: Freshwater transport estimates and the global overturning circulation: Shallow, deep and throughflow components, Prog. Oceanogr., 78, 257-303, 2008.

Thompson, D. W. J. and Solomon, S.: Interpretation of recent Southern Hemisphere climate change, Science, 296, 895-899, 2002.

Toggweiler, J. R., Dixon, K., and Broecker, W. S.: The Peru Upwelling and the Ventilation of the South-Pacific Thermocline, J. Geophys. Res.-Oceans, 96, 20467-20497, 1991.

Toggweiler, J. R. and Samuels, B.: New radiocarbon constraints on the upwelling of abyssal water to the ocean's surface, The Global Carbon Cycle, 333-366, Springer-Verlag, Heidelberg, Germany, 1993.

Toggweiler, J. R. and Carson, S.: What are upwelling systems contributing to the ocean's carbon and nutrient budgets, in: Upwelling in the Ocean: Modern Processes and Ancient Records, edited by: Summerhayes, C. P., Emeis, K.-C., Angel, M. V., Smith, R. L., and Zeitzshel, B., John Wiley and Sons Ltd., 337359, 1995. 
Toggweiler, J. R. and Samuels, B.: Effect of drake passage on the global thermohaline circulation, Deep-Sea Res. Pt. I, 42, 477500, 1995.

Toggweiler, J. R. and Samuels, B.: On the ocean's large-scale circulation near the limit of no vertical mixing, J. Phys. Oceanogr., 28, 1832-1852, 1998.

Trenberth, K., Olsen, J., and Large, W.: A global ocean wind stress climatology based on ECMWF Analyses, National Center for Atmospheric Research, Boulder, Colorado, Technical Report NCAR Tech. Note NCAR/TN-338+str, 93, 1989.
Williams, R. G., Roussenov, V., and Follows, M. J.: Nutrient streams and their induction into the mixed layer, Global Biogeochem. Cy., 20, GB1016, doi:10.1029/2005gb002586, 2006.

Wunsch, C. and Heimbach, P.: Practical global oceanic state estimation, Physica D, 230, 197-208, 2007. 